\title{
Synthesis and Photophysical Properties of Au(III)-Ag(I) Aggregates
}

Julio Fernandez-Cestau, ${ }^{\left[{ }^{[a]}\right.}$ Raquel J. Rama, ${ }^{[a, b]}$ Luca Rocchigiani, ${ }^{[a]}$ Benoit Bertrand, ${ }^{[a]}$ Elena Lalinde, ${ }^{*[c]}$ Mikko Linnolahti, ${ }^{*[\mathrm{~d}]}$ and Manfred Bochmann*[a]

[a] School of Chemistry, University of East Anglia, Norwich, NR4 7TJ, UK.

E-mail: juliofernandez50@gmail.com; m.bochmann@uea.ac.uk

${ }^{[b]}$ Departamento de Química Inorgánica, Universidad de Sevilla, E- 41092 Sevilla, Spain.

[c] Departamento de Química - Centro de Investigación en Síntesis Química. Universidad de La Rioja, 26006, Logroño, Spain.

[d] Department of Chemistry, University of Eastern Finland, Joensuu Campus, Joensuu, Finland

Keywords: Polymetallic systems; photoluminescence; gold complex; tridentate ligands; structure determination; supramolecular assembly.

\begin{abstract}
Cyclometallated gold (III) complexes of the type $\left(\mathrm{C}^{\wedge} \mathrm{N}^{\wedge} \mathrm{C}\right) \mathrm{AuX}\left[\mathrm{HC}^{\wedge} \mathrm{N}^{\wedge} \mathrm{CH}=2,6\right.$-bis $(4-$ $\left.\mathrm{Bu}^{\mathrm{t}} \mathrm{C}_{6} \mathrm{H}_{4}\right)$ pyrazine; 2,6-bis $\left(4-\mathrm{Bu}^{\mathrm{t}} \mathrm{C}_{6} \mathrm{H}_{4}\right)$ pyridine, or 2,6-bis $\left(4-\mathrm{Bu}^{\mathrm{t}} \mathrm{C}_{6} \mathrm{H}_{4}\right) 4$-Butpyridine; $\mathrm{X}$ $=\mathrm{CN}, \mathrm{CH}(\mathrm{COMe})_{2}$ or $\mathrm{CH}(\mathrm{CN})_{2}$ ] have been used as building blocks for the construction of the first family of $\mathrm{Au}^{\mathrm{III}} / \mathrm{Ag}^{\mathrm{I}}$ aggregates. The crystal structures of these aggregates reveal the formation of complex architectures in which the $\mathrm{Ag}^{+}$cations are stabilized by the basic centers present on each of the Au precursors. The photophysical properties of these aggregates are reported. Compared to mononuclear pincer complexes, a general red-shift and an increase in the emission intensity are observed. In agreement with DFT calculations the lowest energy absorption and the emission are assigned to ${ }^{1} \operatorname{IL}\left(\mathrm{C}^{\wedge} \mathrm{N}^{\wedge} \mathrm{C}\right)$ and ${ }^{3} \mathrm{IL}\left(\mathrm{C}^{\wedge} \mathrm{N}^{\wedge} \mathrm{C}\right)$ transitions dominated by the HOMO and the LUMO orbitals.
\end{abstract}

\section{Introduction}

The use of gold(III) complexes in optical devices such as sensors or organic lightemitting diodes (OLEDs) has been a rising area of research in recent years. ${ }^{1}$ In particular, cyclometallated 2-arylpyridine $\left(\mathrm{C}^{\wedge} \mathrm{N}\right)$ and 2,6-diarylpyridine $\left(\mathrm{C}^{\wedge} \mathrm{N}^{\wedge} \mathrm{C}\right)$ 
ligands have been found to be a very effective means of stabilizing $\mathrm{Au}^{\mathrm{III}}$ against

reduction $^{2}$ and, at the same time, generate emissive compounds. In this context, the most successful strategy has proved to be the introduction of strong $\mathrm{C}$-based $\sigma$-donor ligands, such as alkyl, aryl, alkynyl or N-heterocyclic carbenes, in combination with the cyclometallated ligands. This causes the d-d non-radiative transitions to rise in energy and produces pincer ligand-based emissive transitions with triplet parentage. , $^{3,4}$

The modulation of the emission wavelengths is usually achieved by modifying either the pincer or the ancillary ligand with substituents of different electronic characteristics, in order to adjust the orbitals responsible for the emission. However, this approach requires a significant synthetic effort. For this reason, having access to less laborious ways of tuning the emission in this type of complexes continues to be a focus of interest. With this in mind, recent studies have been directed towards post-synthetic modulation of photoemissions through the formation of multinuclear architectures and metallogels with supramolecular aggregation, ${ }^{5}$ as well as the exploitation of alternative emissive pathways, such as thermally activated delayed fluorescence (TADF) ${ }^{6,7}$

In 2015 we reported the synthesis of the first family of $\mathrm{C}^{\wedge} \mathrm{N}^{\wedge} \mathrm{C}$ pincer complexes with pyrazine instead of pyridine as the central ring. ${ }^{6}$ This simple change has important consequences from a photophysical point of view: Firstly, the pyrazine-based complexes show increased photoluminescence intensities in comparison with the pyridine analogues, and secondly, the $\pi-\pi^{*}$ gap in pyrazine is around $0.95 \mathrm{eV}$ smaller than in pyridine, so that the pyrazine pincer becomes a better electron acceptor and the presence of strong $\sigma$-donating ancillary ligands is no longer mandatory to generate luminescent complexes. These pyrazine complexes provided the first examples of gold(III) complexes showing TADF behavior.

A remarkable case for the difference in photoluminescence (PL) of pyridine $v s$. pyrazine (pz) based $\mathrm{C}^{\wedge} \mathrm{N}^{\wedge} \mathrm{C}$ gold pincer complexes are the thiolates, $\left(\mathrm{C}^{\wedge} \mathrm{N}^{\mathrm{pz}} \mathrm{C}\right) \mathrm{AuSR}$ $(\mathrm{R}=\mathrm{Ph}$, naphthyl, 1-adamantyl), which are strongly photoemissive at room temperature, unlike their pyridine analogues. The photoluminescence of $\left(\mathrm{C}^{\wedge} \mathrm{N}^{\mathrm{pz} \wedge} \mathrm{C}\right) \mathrm{AuSR}$ was due to ${ }^{3} \mathrm{IL}\left(\mathrm{C}^{\wedge} \mathrm{N}^{\mathrm{pz} \wedge} \mathrm{C}\right)$ emissions which, unusually, turned out to be modulated by aggregation through pyrazine-pyrazine interactions, leading to a strong red-shift from a $\pi$-stacked bimolecular emissive state. ${ }^{8}$

The strategy of triggering new emissive states by the formation of homo-and heteropolymetallic architectures through the formation of metallophilic interactions has been particularly successful in gold chemistry, but only for gold in the oxidation state 
$+\mathrm{I} .{ }^{9}$ Supramolecular aggregates have also been described for $\mathrm{Pt}^{\mathrm{II}},{ }^{10}$ which is

isoelectronic with $\mathrm{Au}^{\mathrm{III}}$. In contrast, there is little evidence for metallophilic interactions in $\mathrm{Au}^{\mathrm{III}}$ chemistry. ${ }^{11}$

Nevertheless, this is no reason to discard $\mathrm{Au}^{\mathrm{III}}$ complexes as building blocks for the construction of photoemissive supramolecular assemblies, as other basic functionalities of the molecule could act as binding points for other metals. In fact, we observed earlier that the emission of the pyrazine-based alkynyl complex $\left[\left(\mathrm{C}^{\wedge} \mathrm{N}^{\mathrm{pz} \wedge} \mathrm{C}\right) \mathrm{AuC} \equiv \mathrm{CPh}\right]$ was red-shifted on addition of $\mathrm{Ag}^{+}$ions. However, despite numerous attempts neither the precise structure of this $\mathrm{Ag}^{\mathrm{I}} / \mathrm{Au}^{\mathrm{III}}$ aggregate nor the origin of the shift in emissions could be elucidated. ${ }^{6}$

Here we present a family of structurally characterized luminescent heteropolynuclear systems involving $\mathrm{Au}$ III, to our knowledge the first such examples.

The use as building blocks of cyclometallated pyrazine $\mathrm{Au}^{\mathrm{III}}$ systems with secondary basic residues such as cyanide $\left[\left(\mathrm{C}^{\wedge} \mathrm{N}^{\mathrm{pz} \wedge} \mathrm{C}\right) \mathrm{AuCN}\right],{ }^{6} \mathrm{C}$-bound acetylacetonate $\left[\left(\mathrm{C}^{\wedge} \mathrm{N}^{\mathrm{pz} \wedge} \mathrm{C}\right) \mathrm{Au}(\mathrm{acac})\right] \quad\left(\mathrm{acac}=\mathrm{CH}(\mathrm{C}(\mathrm{O}) \mathrm{Me})_{2}\right)$ or malononitrile $\left[\left(\mathrm{C}^{\wedge} \mathrm{N}^{\mathrm{pz} \wedge} \mathrm{C}\right) \mathrm{AuCH}(\mathrm{CN})_{2}\right]^{12}$ in reactions with $\mathrm{Ag}^{\mathrm{I}}$ salts has allowed the isolation of polymetallic aggregates with a wide range of nuclearities and bonding motifs. The photophysical properties of these aggregates are intimately correlated with the nature of the supramolecular assembly, as has been probed by theoretical calculations. Similar $\mathrm{Au}^{\mathrm{III}}-\mathrm{Ag}^{\mathrm{I}}$ systems using pyridine-based analogues have been also prepared for comparison and illustrate the implications for the structures and photoluminescence of these assemblies.

\section{Results and Discussion}

Synthesis and X-Ray Structures. Slow diffusion of THF solutions of AgSbF or $\mathrm{AgClO}_{4}$ into light-yellow dichloromethane solutions of $\left(\mathrm{C}^{\wedge} \mathrm{N}^{\mathrm{pz} \wedge} \mathrm{C}\right) \mathrm{AuCN}$ [ $\left.{ }^{\mathrm{pz}} \mathrm{Au}\right] \mathbf{C N}$ resulted in the precipitation of the $2: 1$ adducts $\left[\left\{\left(\mathrm{C}^{\wedge} \mathrm{N}^{\mathrm{pz} \wedge} \mathrm{C}\right) \mathrm{AuCN}\right\}_{2} \mathrm{Ag}\right] \mathrm{X}\left(\mathrm{X}=\mathrm{SbF}_{6}\right.$ 1SbF6, $\mathrm{ClO}_{4} \mathrm{1ClO}_{4}$ ) as orange solids (Scheme 1). Due to their low solubility in common organic solvents the compounds were prepared as orange crystals by direct synthesis in H-shaped crystallization tubes (see Figure 1 and ESI for experimental details). 


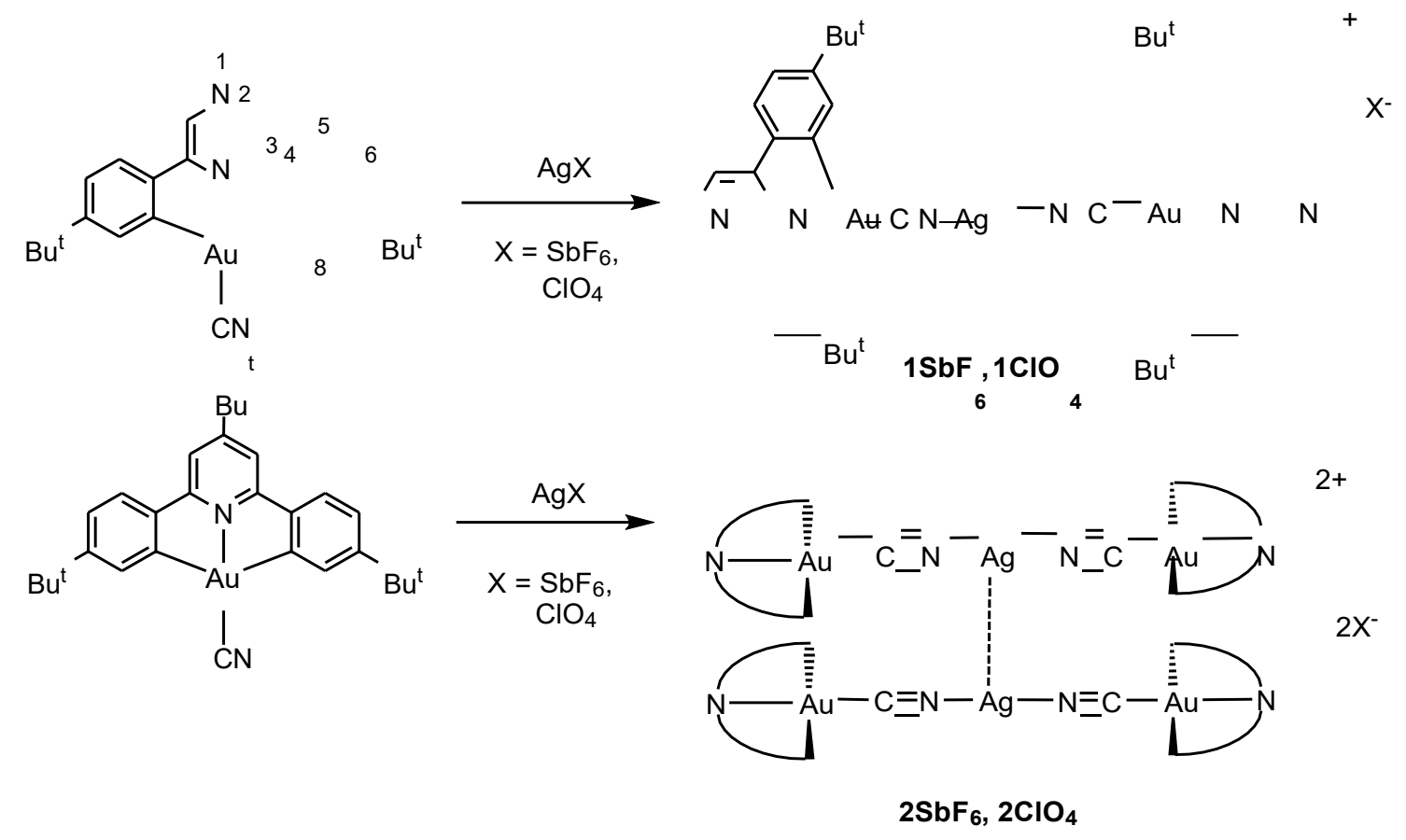

Scheme 1. Synthesis of cyano-bridged aggregates, including the numbering used for NMR assignments.

While the crystal quality of $\left[\left\{\left(\mathrm{C}^{\wedge} \mathrm{N}^{\mathrm{pz} \wedge} \mathrm{C}\right) \mathrm{AuCN}\right\}_{2} \mathrm{Ag}\right]\left(\mathrm{SbF}_{6}\right) \quad \mathbf{1 S b F}_{6}$ was insufficient for a detailed discussion of the structural parameters, the connectivity could be unequivocally established and confirmed the identity of the complex as a trinuclear species in which two gold fragments are connected by a CN-Ag-NC bridge. The crystal packing shows numerous intermolecular interactions of each trinuclar entity with its neighbors through a combination of $\mathrm{Ag} \cdots \mathrm{C}_{64}^{\mathrm{H}}{ }_{4}^{\mathrm{Bu}}-4$ and $\pi \cdots \pi$ stacking, which may explain the low solubility of these systems. The coordination of the $\mathrm{Ag}^{\mathrm{I}}$ ions to the cyanide ligands is reflected in the shift of the IR $v(C \equiv N)$ stretching band to higher frequencies with respect to the starting material (from $2173 \mathrm{~cm}^{-1}$ in $\left[{ }^{\mathbf{p z}} \mathbf{A u}\right] \mathbf{C N}$ to 2220 $\mathrm{cm}^{-1}$ in $\mathbf{1 C l O}$ and 2225 in $\left.\mathbf{1 S b F}\right)_{6}{ }^{13}$ 


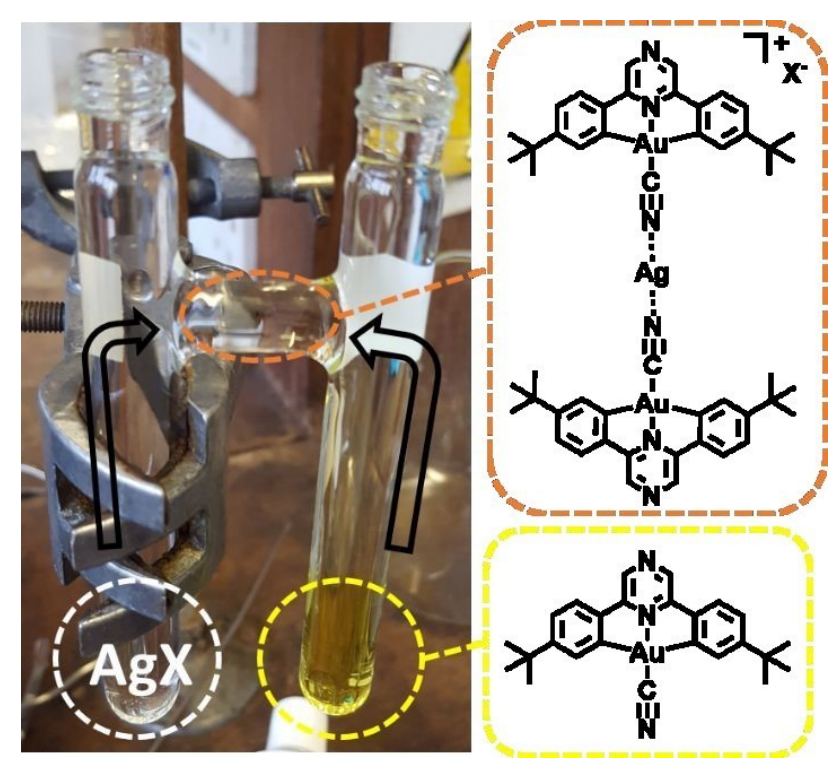

Figure 1. Crystallization set-up for the direct synthesis of $\mathbf{1 S b F}_{\mathbf{6}}$ and $\mathbf{1 C l O}_{4}$.

The analogous pyridine complexes $\left[\left\{\left(\mathrm{C}^{\wedge} \mathrm{N}^{\mathrm{tBu} \wedge} \mathrm{C}\right) \mathrm{AuCN}\right\}_{2} \mathrm{Ag}\right] \mathrm{X}\left(\mathrm{X}=\mathrm{SbF}_{6} \mathbf{2} \mathbf{S b F}_{\mathbf{6}}\right.$, $\left.\mathrm{ClO}_{4} \mathbf{2} \mathbf{C l O} 4\right)$ are accessible by treatment of $\left(\mathrm{C}^{\wedge} \mathrm{N}^{\mathrm{tBu} \wedge} \mathrm{C}\right) \mathrm{AuCN}\left[{ }^{\mathbf{t B u}-\mathbf{p y}} \mathbf{A u}\right] \mathbf{C N}$ with the corresponding silver salts in THF. The X-ray structure of $\mathbf{2 S b F}_{\mathbf{6}}($ Figures 2a and S2.1) reveals that the trinuclear cationic units $\left[\left\{\left(\mathrm{C}^{\wedge} \mathrm{N}^{\mathrm{tBu} \wedge} \mathrm{C}\right) \mathrm{AuCN}\right\}_{2} \mathrm{Ag}\right]^{+}$dimerize through the formation of unsupported argentophilic interactions, with a silver-silver distance of 3.103(1) $\AA$, much shorter than the sum of the van der Waals radii of two silver atoms (3.44 A). ${ }^{14}$ However, it has been recently established that the concept of 'unsupported' interactions might underestimate the impact that other aggregation forces, such as hydrogen bonding or $\pi-\pi$ stacking, can have on co-determining the Ag-Ag distance, and that the correlation between shorter distance and stronger bond can be misleading given the particular character of argentophilicity. ${ }^{15}$ The $\mathrm{CN}-\mathrm{Ag}-\mathrm{NC}$ moieties in $\left[\left\{\left(\mathrm{C}^{\wedge} \mathrm{N}^{\mathrm{tBu} \wedge} \mathrm{C}\right) \mathrm{AuCN}\right\}_{2} \mathrm{Ag}\right] 2_{2}{ }^{2+}$ deviate from the expected linearity, with $\mathrm{N}-\mathrm{Ag}-\mathrm{N}$ anglesof 160.2(3) and $165.7(3)^{\circ}$ to accommodate the Ag-Ag interaction. This distortion from linearity is particularly pronounced when compared, for example, with that observed in the argentophilic-based columnar arrangement of $\left[\mathrm{Ag}(\mathrm{py})_{2}\right]^{+}$cations (average N-Ag-N angle $\left.175^{\circ}\right) .{ }^{16}$ 

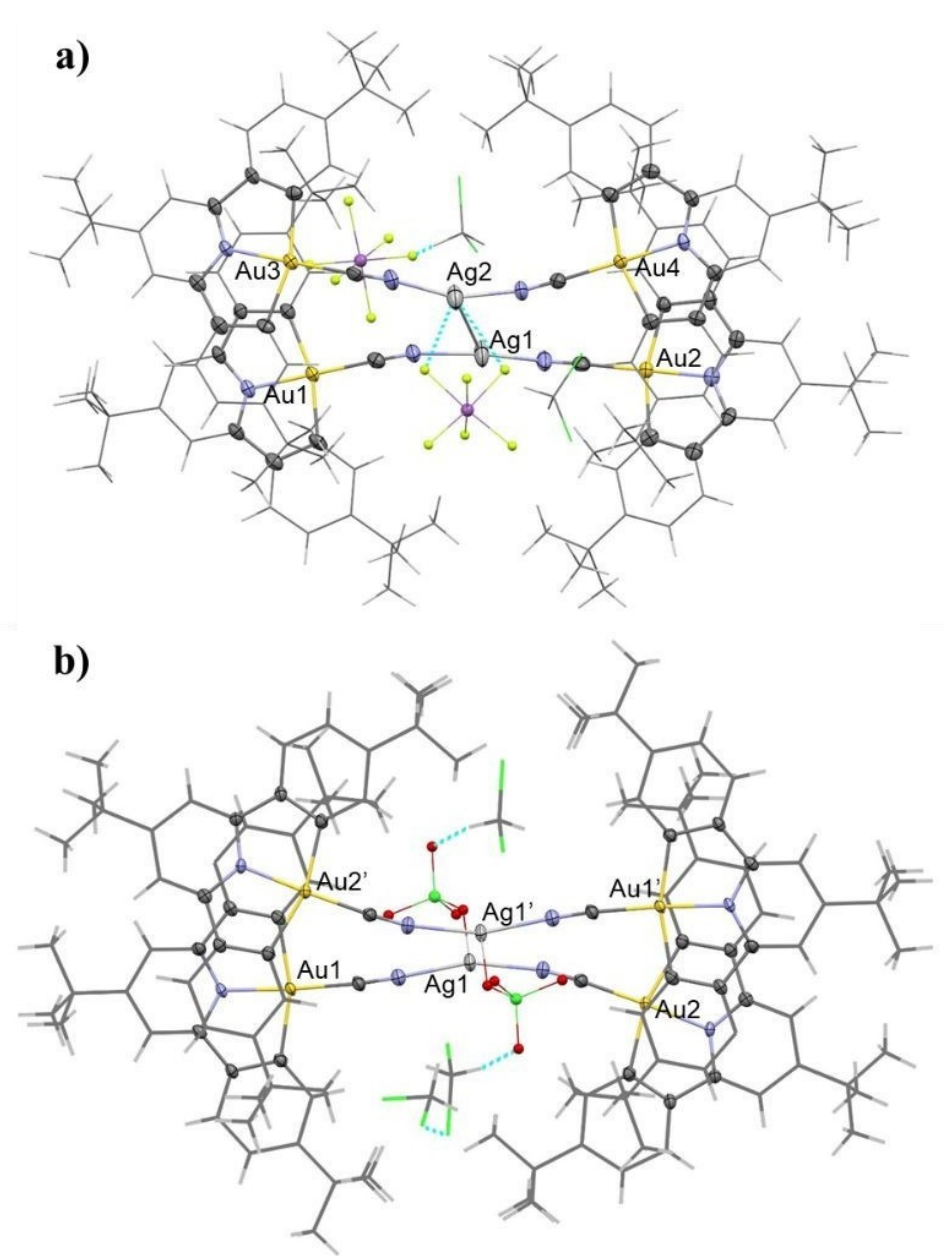

Figure 2. Top views of the $\mathrm{X}$-ray structures of $\left[\left\{\left(\mathrm{C}^{\wedge} \mathrm{N}^{\mathrm{tBu} \wedge} \mathrm{C}\right) \mathrm{AuCN}\right\}_{2} \mathrm{Ag}\right]_{2}\left[\mathrm{SbF}_{6}\right]_{2} \cdot 3$ $\mathrm{CH} \mathrm{Cl} \mathrm{2SbF} \cdot 3 \mathrm{CH} \mathrm{Cl}$ (a) and $\left[\left\{\left(\mathrm{C}^{\wedge} \mathrm{N}^{\mathrm{tBu} \wedge} \mathrm{C}\right) \mathrm{AuCN}\right\} \mathrm{Ag}\right][\mathrm{SbF}] \cdot 3 \mathrm{CH} \mathrm{Cl} \mathrm{2ClO}$ $\cdot 3 \stackrel{2}{\mathrm{C}} \stackrel{2}{\mathrm{H}} \mathrm{Cl}(\mathbf{b})$. The structures are shown as stick based skeleton with only the most relevant atoms represented as ellipsoids with 50\% probability level.

In the $\mathrm{SbF}-\mathrm{salt}$ the anions play a spectator role in the stabilization of the structure; one of the anions interacts weakly with one of the Ag centers, while the other silver ion interacts with a $\mathrm{CH}_{2} \mathrm{Cl}_{2}$ molecule. By contrast, the anions in $\left[\left\{\left(\mathrm{C}^{\wedge} \mathrm{N}^{\mathrm{tBu} \wedge} \mathrm{C}\right) \mathrm{AuCN}\right\}_{2} \mathrm{Ag}\left(\mathrm{ClO}_{4}\right)\right]_{2} \cdot 3 \mathrm{CH}_{2} \mathrm{Cl}_{2}\left(\mathbf{2} \mathrm{ClO}_{4} \cdot 3 \mathrm{CH}_{2} \mathrm{Cl}_{2}\right)$ are bound more strongly to the $\mathrm{Ag}^{+}$centers, as indicated by the short Ag-O distance (2.584(4) $\AA$ ), giving a Tshaped coordination environment for $\mathrm{Ag}$, with additional contacts to dichloromethane molecules. As a consequence of the perchlorate coordination to $\mathrm{Ag}^{+}$, argentophilic interactions are absent, and the Ag-Ag distance is elongated to 3.3881(5) $\AA$. The topview of both structures (Figure 2) illustrates the distortion of the trinuclear entities to accommodate the Ag-Ag interaction. 
Treatment of $\mathrm{CH}_{2} \mathrm{Cl}_{2}$ solutions of $\left(\mathrm{C}^{\wedge} \mathrm{N}^{\mathrm{pz} \wedge} \mathrm{C}\right) \mathrm{Au}(\mathrm{acac})\left[{ }^{\mathrm{pz}} \mathrm{Au}\right] \mathbf{a c a c}$ with an excess of $\mathrm{AgX}\left(\mathrm{X}=\mathrm{ClO}_{4}, \mathrm{SbF}_{6}\right)$ produced a noticeable change in color from light yellow to deep orange. Orange microcrystalline solids with an $\mathrm{Au}: \mathrm{Ag}$ ratio of 1:1 were isolated from these solutions (Scheme 2).

N

$\mathrm{Bu}^{\mathrm{t}}$

$$
\mathrm{N}
$$

O 0

N

$\mathrm{Bu}^{\mathrm{t}}$

$$
\mathrm{Au}
$$$$
\text { o } 0
$$

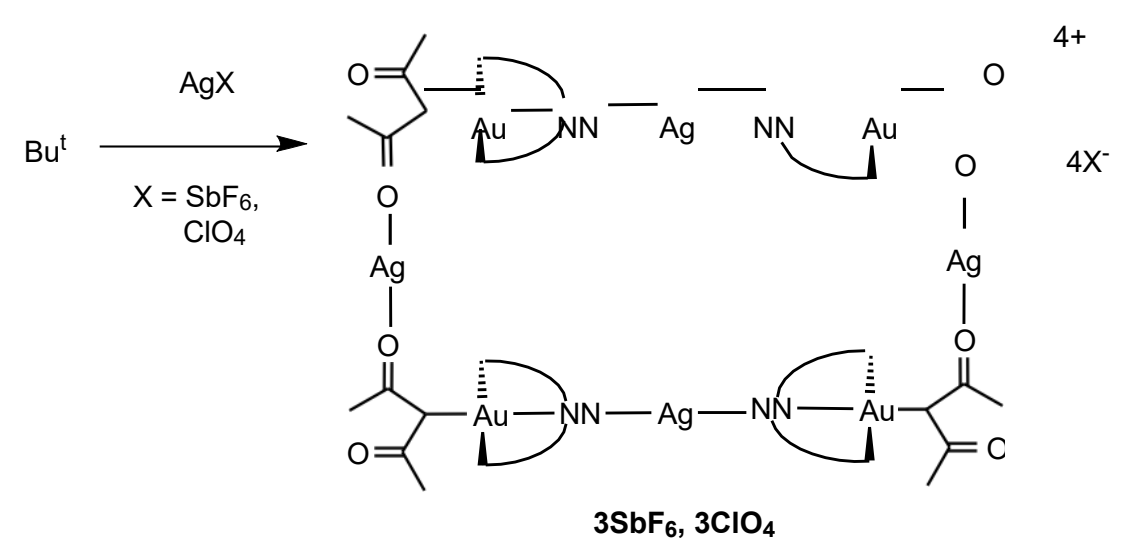

Scheme 2. Synthesis of acac aggregates.

Slow diffusion of pentane into $\mathrm{CH}_{2} \mathrm{Cl}_{2}$ solutions afforded crystals suitable for $\mathrm{X}$ Ray diffraction analysis. As is shown in Figure 3, both structures show an octanuclear [Au $\left.4 \mathrm{Ag}_{4}\right]$ arrangement in which the silver ions adopt two types of coordination environments that are noticeably different from each other: One Ag ion, labelled Ag1, is sandwiched by two $[\mathrm{Au}]$ fragments and bound to one acac-O atom of each $[\mathrm{Au}]$ fragment. In addition, Ag1 forms a $\pi$-bond with one aryl ring of the cyclometallated ligand of each of the $[\mathrm{Au}]$ fragments, in a manner similar to that of other Ag- $\pi$-arene complexes, ${ }^{17}$ which leads to a distorted tetrahedral coordination environment for Ag1. The second silver ion, $\mathrm{Ag} 2$, is coordinated to nitrogen atoms of the pyrazine rings of two trinuclear units. Detailed views for both structures can be found in Figures S2.3 and S2.4). 
The Ag1-Au distances (Ag1-Au1 3.004(1) Å and Ag1-Au2 2.993(1) Å for 3SbF6;

Ag1-Au1 2.9419(7) $\AA, A g 1-A u 2 ~ 3.0737(6) \AA$ for 3C1O4) are shorter than the sum of the Van der Waals radii of both atoms $\left(\mathrm{r}^{\mathrm{Ag}} 1.72+\mathrm{r}^{\mathrm{Au}} 1.66=3.38 \AA\right)$. The asymmetry of the $\mathrm{Ag} \cdots \mathrm{C}=\mathrm{C}$ interaction and the close approach of $\mathrm{Ag}^{+}$towards the carbon directly bound to $\mathrm{Au}$ indicates that these interactions are predominantly controlled by Coulomb attractions.

The bonding of Ag2 to the two $\mathrm{N}$ atoms of the pyrazine rings (Ag2-N2 2.19(1) $\AA$ and Ag2-N4' 2.16(2) Å 3SbF6; Ag2-N2 2.244(6) $\AA$ and Ag2-N4' 2.241(5) $\AA$ 3ClO4) is substantially longer than $\mathrm{Ag}^{+}$bonding to cyanide in $\mathbf{2 C l O}_{4}$ and $\mathbf{2} \mathrm{SbF}_{6}$ (see before $\mathrm{Ag}-\mathrm{N}$ $\sim 2.10 \AA$ ). In the case of $\mathbf{3 C l O}_{4}$, the two silver ions $\mathrm{Ag} 2$ and $\mathrm{Ag} 2$ ' are further held together by two asymmetrically bridging perchlorate ions, with an Ag2-O distances of 2.52(1) and 2.657(9). Two further perchlorate ions are $\kappa^{1}$-bonded (Ag2-O5 2.584(6) $\AA$ ).

However, the coordination environment of the Ag2 ions is strongly influenced by the nature of the anion. Thus, for $\mathbf{3 S b F}{ }_{6}$ the lower coordinating character of the SbF ${ }_{6} 6$ drives to shorter Ag-N distances with the pyrazines (Ag2-N2 2.18(1) $\AA$ and Ag2-N4' 2.16(2) $\AA$ ). Nevertheless, the general arrangement of the interaction with the anions is maintained through $\mathrm{Ag} \cdots \mathrm{F}$ interactions. 

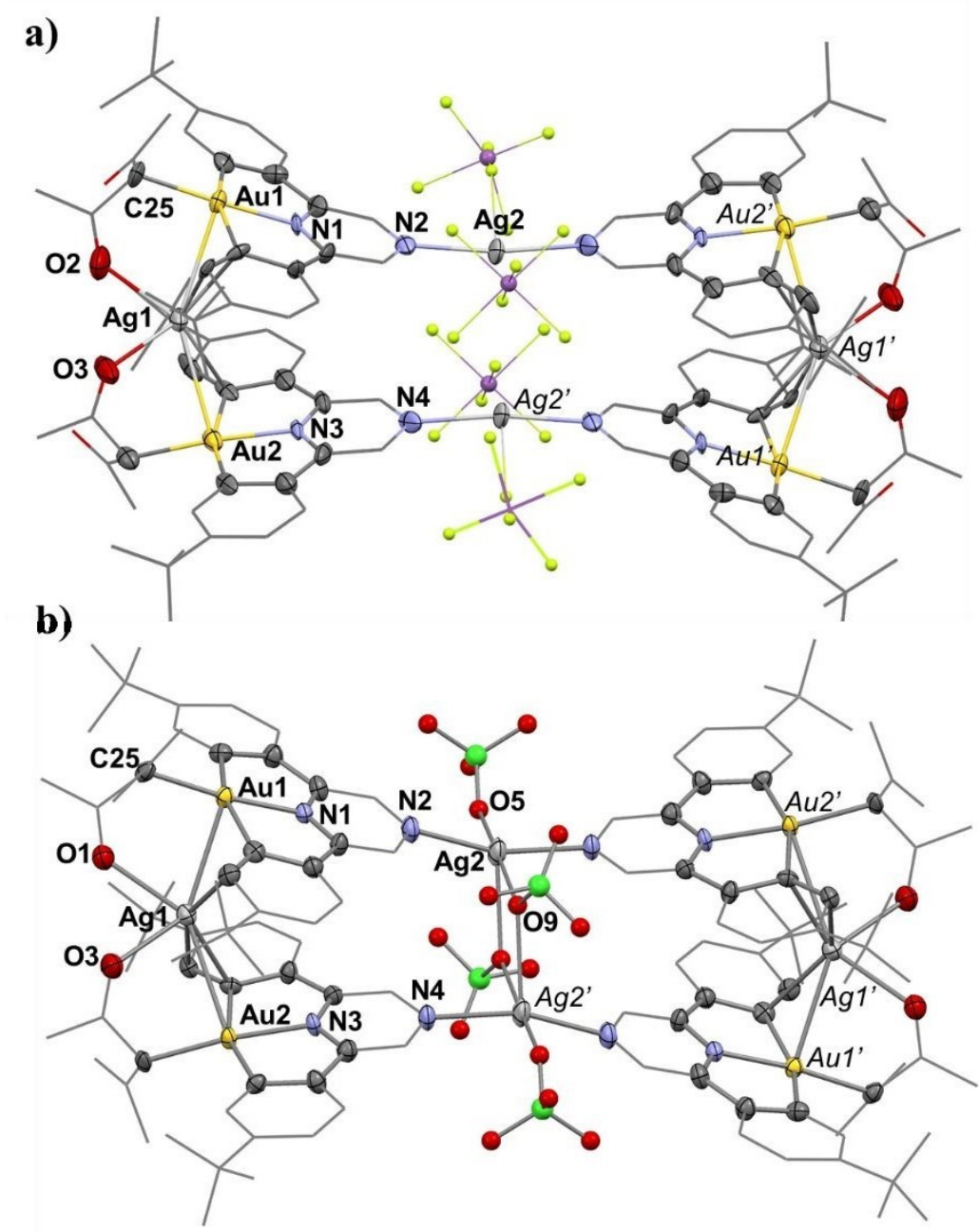

Figure 3: Molecular view of the $\mathrm{X}$-ray structure of (a) $\mathbf{3 S b F}_{6} \cdot 6 \mathrm{C}_{7} \mathrm{H}_{8}$ and (b)

3ClO $4 \cdot 1.5 \mathrm{CH}_{2} \mathrm{Cl}_{2} \cdot 2 \mathrm{C}_{5} \mathrm{H}_{12}$. The solvent molecules and hydrogen atoms are omitted for

clarity. The structures are shown as stick based skeleton with only the most relevant atoms represented as ellipsoids with $50 \%$ probability level.

The analogous pyridine precursor $\left(\mathrm{C}^{\wedge} \mathrm{N}^{\mathrm{py} \wedge} \mathrm{C}\right) \mathrm{Au}(\mathrm{acac})$ [ ${ }^{\mathbf{p y}} \mathrm{Au}$ ] acac reacts with an excess of $\mathrm{AgSbF}$ in $\mathrm{CH} \mathrm{Cl}{ }_{6} \quad$ with a noticeable change of color from light to deep yellow. Slow diffusion of pentane generated crystals suitable for X-Ray diffraction analysis. As it is shown in Figure 4, the absence of a basic nitrogen atom in the pincer precludes the formation of $\mathrm{Ag}-\mathrm{N}$ bonds and the stoichiometry of the complex is $\mathrm{Au} / \mathrm{Ag}$ $=2: 1$, with the silver cation sandwiched between two $[\mathrm{Au}]$ fragments, in a manner similar to that of Ag1 in the pyrazine structures. The most noticeable difference is that the $\mathrm{Ag}$ bonding to the $\mathrm{C}=\mathrm{C} \pi$-bonds to aryl rings of the cyclometallated ligands is less asymmetric (Ag1-C7 2.453(8), Ag1-C37 2.432(8) Å; Ag1-C8 2.558(8), Ag1-C38 2.591(8) A). 


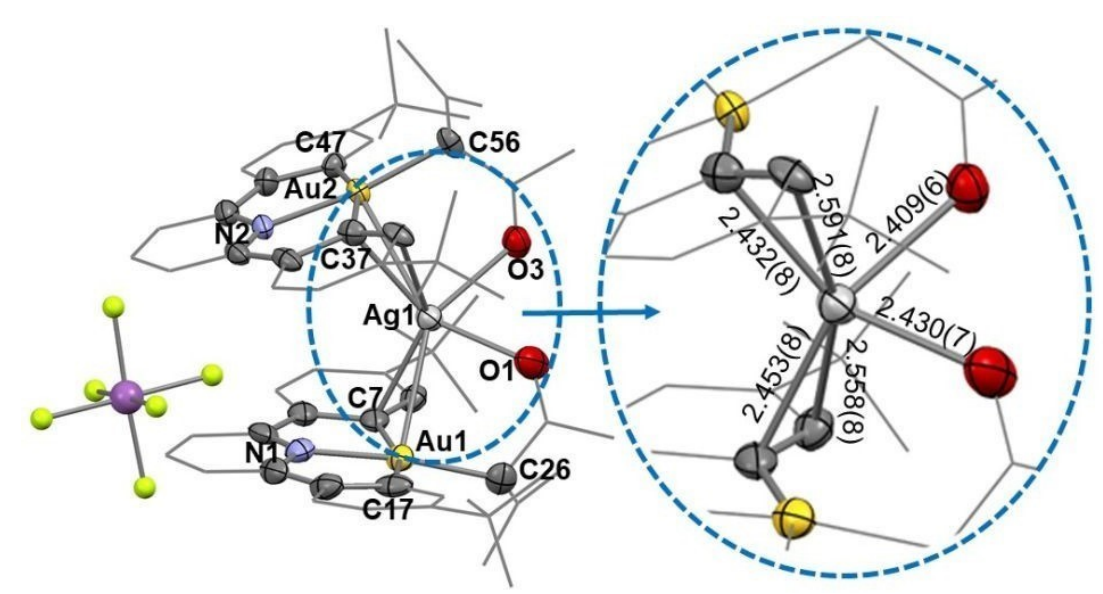

Figure 4: Molecular view of the complex $\left.\left[\left\{\left(\mathrm{C}^{\wedge} \mathrm{N}^{\mathrm{py} \wedge} \mathrm{C}\right) \mathrm{Au}(\mathrm{acac})\right\}_{2} \mathrm{Ag}\right\}\right]\left(\mathrm{SbF}_{6}\right) \cdot \mathrm{CH}_{2} \mathrm{Cl}_{2}$

$\mathbf{4 S b F}_{6} \cdot \mathrm{CH}_{2} \mathrm{Cl}_{2}$. The solvent molecule and the hydrogen atoms are omitted for clarity.

The structure is shown as stick based skeleton with only the most relevant atoms represented as ellipsoids with 50\% probability level. Selected bond distances $(\AA)$ and angles $\left({ }^{\circ}\right)$ : Au1-C26 2.057(9), Au1-C7 2.092(8), Au1-C17 2.078(9), Au1-N1 2.017(7), Au2-C56 2.071(8), Au2-C37 2.114(8), Au2-C47 2.060(8), Au2-N2 2.024(6), Ag1-O1 2.430(7), Ag1-O3 2.409(6), Ag1-C7 2.453(8), Ag1-C8 2.558(8), Ag1-C37 2.432(8), Ag1-C38 2.591(8), C7-Au1-C26 103.0(3), C17-Au1-C26 95.6(3), C7-Au1-N1 80.8(3), C17-Au1-N1 81.0(3), C26-Au1-N1 172.7(3), C7-Au1-C17 161.2(3), C37-Au2-N2 80.5(3), C47-Au2-N2 81.3(3), C37-Au2-C56 102.7(3), C47-Au2-C56 95.5(3), C37Au2-C47 161.8(3), C56-Au2-N2 172.1(3), O1-Ag1-O3 75.1(2), O1-Ag1-centroid(C37C38) 113.50, O3-Ag1-centroid(C7-C8) 120.57, centroid(C7-C8)-Ag1-centroid(C37C38) 136.80 .

A $\mathrm{CH}_{2} \mathrm{Cl}_{2}$ solution of $\left(\mathrm{C}^{\wedge} \mathrm{N}^{\mathrm{pz} \wedge} \mathrm{C}\right) \mathrm{Au}$ (malononitrile) $\left[{ }^{\mathrm{pz}} \mathrm{Au}\right] \mathbf{m l n}$ reacted with $\mathrm{AgSbF}_{6}$, generating a light orange solid of composition $\left\{\left[\left\{\left(\mathrm{C}^{\wedge} \mathrm{N}^{\mathrm{pz} \wedge} \mathrm{C}\right) \mathrm{Au}(\text { malononitrile })\right\}_{2} \mathrm{Ag}(\mathrm{THF})\right]\left(\mathrm{SbF}_{6}\right)\right\}_{\mathrm{n}} \quad \mathbf{5 S b F}_{\mathbf{6}} \quad$ (Scheme $\left.\quad 3\right) . \quad$ This compound shows low solubility in $\mathrm{CH} \mathrm{Cl}$ but can be dissolved in THF. Slow pentane diffusion led to orange crystals suitable for X-ray crystallography. 


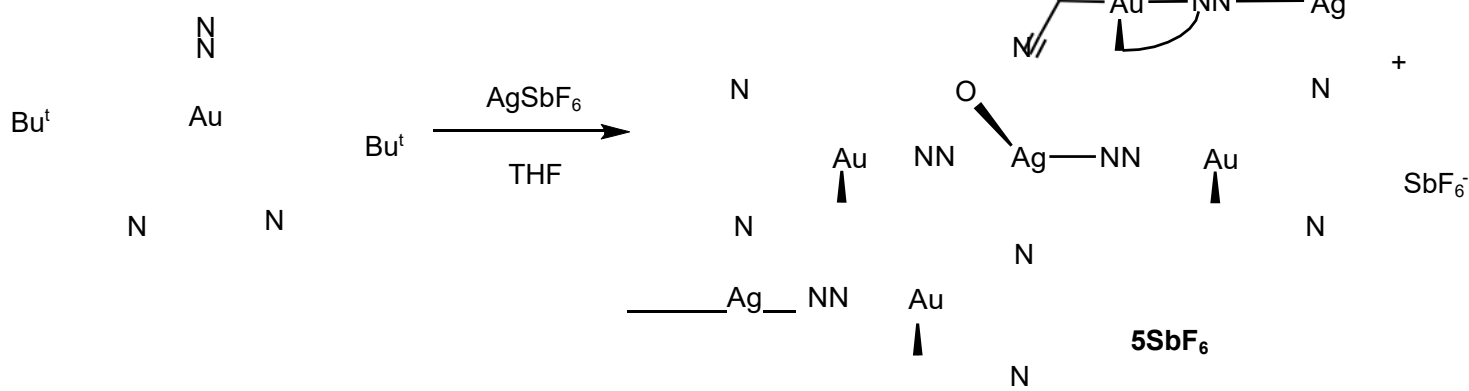

Scheme 3: Synthesis of malononitrile aggregates.

The asymmetric unit shows one gold malononitrile fragment $\left(\mathrm{C}^{\wedge} \mathrm{N}^{\mathrm{p}} \wedge \mathrm{C}\right) \mathrm{Au}$ (malononitrile) and one silver cation with occupancy $1 / 2$ as it lies on a twofold rotational axis (Figure 5). Each $\mathrm{Ag}^{+}$ion binds to four different $\left(\mathrm{C}^{\wedge} \mathrm{N}^{\mathrm{p}} \wedge \mathrm{C}\right) \mathrm{Au}$ (malononitrile) molecules, as well as to one THF ligand. Two of the $\left(\mathrm{C}^{\wedge} \mathrm{N}^{\mathrm{p}} \wedge \mathrm{C}\right) \mathrm{Au}$ (malononitrile) building blocks are bound by one malononitrile $\mathrm{CN}$ unit, with rather short Ag-N bonds (Ag1-N4" 2.212(5) $\AA$ ), the other two are bonded via their pyrazine-N atoms, with longer Ag-N interactions (Ag1-N2 2.476(5) $\AA$ ). This generates a distorted square-pyramidal $\mathrm{AgN}_{4} \mathrm{O}$ linking unit, which connects the assembly to give 1D rods in the direction of the crystallographic $c$ axis, with the $\mathrm{SbF}_{6}^{-}$anions in the interstitial spaces between the rods. 


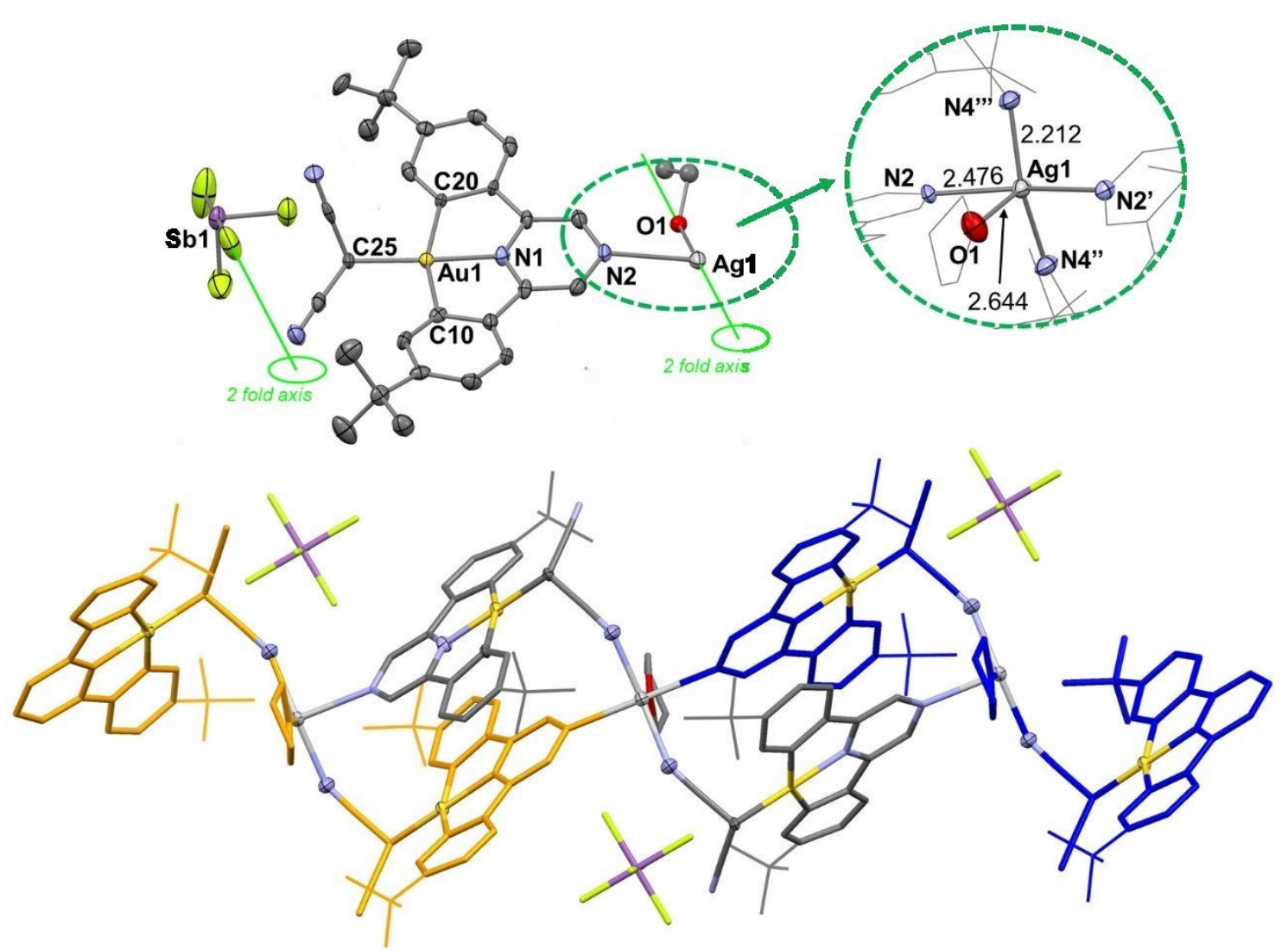

Figure 5: Molecular view of the complex $\left\{\left[\left\{\left(\mathrm{C}^{\wedge} \mathrm{N}^{\mathrm{pz} \wedge} \mathrm{C}\right) \mathrm{Au}(\text { malononitrile })\right\}_{2} \mathrm{Ag}\right.\right.$ $\left.(\mathrm{THF})]\left(\mathrm{SbF}_{6}\right)\right\}_{\mathrm{n}}\left(\mathbf{5 S b F}_{\mathbf{6}}\right)$. Hydrogen atoms are omitted for clarity. The structure is shown as stick based skeleton with only the most relevant atoms represented as ellipsoids with 50\% probability level. Selected bond distances $(\AA \AA)$ and angles $\left(^{\circ}\right)$ : Au1C25 2.088(6), Au1-C10 2.087(6), Au1-C20 2.102(6), Au1-N1 2.015(5), Ag2-N2 2.476(5), Ag1-N4" 2.212(5), Ag1-O1 2.644, C10-Au1-N1 80.6(2), C20-Au1-N1 79.6(2), C10-Au1-C25 94.2(2), C20-Au1-C25 105.7(2), N1-Au1-C25 174.4(2), C10Au1-C20 160.0(2), N2-Ag1-N4" 92.3, N2-Ag1-O1 84.0, N4"-Ag1-O1 99.6, N2-Ag1N2 167.9, N4"-Ag1-N"'160.7.

NMR characterization in solution. In order to understand whether such aggregations persist in solution, we studied the behavior of these complexes by means of NMR spectroscopy. The pyrazine cyanide silver complexes show very low solubility in common organic solvents, so they could not be investigated. In contrast, the analogous complexes with p-tBu pyridine as the central ring of the pincer $\left[\left\{\left(\mathrm{C}^{\wedge} \mathrm{N}^{\mathrm{tBu} \wedge} \mathrm{C}\right) \mathrm{AuCN}\right\}_{2} \mathrm{Ag}\right] \mathrm{X}\left(\mathrm{X}=\mathrm{SbF}_{6} \mathbf{2 S b F}_{6}, \mathrm{ClO}_{4} \mathbf{2 C l O}_{4}\right)$ are soluble enough to be fully characterized by NMR spectroscopy. Their ${ }^{1} \mathrm{H}$ NMR spectra in $\mathrm{CD}_{2} \mathrm{Cl}_{2}$ show a shift of the signals with respect to the mononuclear gold precursor. For example, the 
doublet corresponding to $\mathrm{H}^{8}$, which is a convenient reporter signal in this type of complexes, is appreciably low-frequency shifted when compared with the starting precursor $\left(\Delta \delta 0.09 \mathbf{2 S b F}{ }_{6}\right.$ and $\left.0.07 \mathrm{ppm} \mathbf{2 C l O}_{4}\right)$. Quite reasonably, this indicates that the trinuclear fragment persists in solution. There is not much effect of the anion on the chemical shift, suggesting that even more coordinating anions such as $\mathrm{ClO}_{4}^{-}$are not capable of dissociating the $\left[\mathrm{Au}_{2} \mathrm{Ag}\right]$ unit. Unfortunately, we were unable to observe a signal for the cyanide moiety in the ${ }^{13} \mathrm{C}\left\{{ }^{1} \mathrm{H}\right\}$ NMR spectra. For this reason, we decided to synthesize the ${ }^{13} \mathrm{C} \equiv \mathrm{N}$ analogues (see $\mathrm{ESI}$ ), which confirm that the ${ }^{13} \mathrm{C}$ NMR cyanide signals for both complexes are high-frequency shifted with respect to the mononuclear precursors: $\left(\mathrm{C}^{\wedge} \mathrm{N}^{\mathrm{tBu} \wedge} \mathrm{C}\right) \mathrm{Au}^{13} \mathrm{CN}$ resonates at $\delta_{\mathrm{C}}=115.9 \mathrm{ppm}$, while both aggregates $\left[\left\{\left(\mathrm{C}^{\wedge} \mathrm{N}^{\mathrm{tBu} \wedge} \mathrm{C}\right) \mathrm{AuCN}\right\}{ }_{2}^{\mathrm{Ag}}\right] \mathrm{X}\left(\mathrm{X}=\mathrm{SbF}{ }_{6} \mathbf{2 S b F}_{\mathbf{6}}, \mathrm{ClO}_{4} \mathbf{2 C l O}_{4}\right)$ show signals at $=124.3$ ppm. ${ }^{18}$ $\delta_{\mathrm{C}}$

The ${ }^{1} \mathrm{H}$ NMR spectra of the acac derivatives $\left[\left\{\left\{\left(\mathrm{C}^{\wedge} \mathrm{N}^{\mathrm{pz} \wedge} \mathrm{C}\right) \mathrm{Au}(\mathrm{acac})_{2}\right\}_{2} \mathrm{Ag}\right\}-\right.$ $\left.\left\{\mathrm{Ag}_{2} \mathrm{X}_{4}\right\}\right]_{2}\left(\mathrm{X}=\mathrm{SbF}_{6} \mathbf{3 S b F}_{6}, \mathrm{ClO}_{4} \mathbf{3 C l O}_{4}\right)$ show very broad signals in $\mathrm{CD}_{2} \mathrm{Cl}_{2}$ at room temperature and they are superimposable with each other, with the exception of $\mathrm{H}^{2}$. The latter is high-frequency shifted for $\mathbf{3 C l O}_{4} \quad\left(\delta_{\mathrm{H}}=9.62 \mathrm{ppm}\right)$ by comparison with $\mathbf{3} \mathbf{S b F}_{6}$ $\left(\delta_{\mathrm{H}}=9.09 \mathrm{ppm}\right)$, likely reflecting a different type of interaction between silver, anion and pyrazine ring, as was also observed at the solid state. Sharp and well resolved spectra are obtained upon cooling the samples at temperatures below $-20{ }^{\circ} \mathrm{C}$. The ${ }^{1} \mathrm{H}$ NMR spectra obtained at low temperature show the presence of two sets of signals for the pincer ligand, together with two different methyl signals for the acac moiety.

Interestingly, only one signal for the $\mathrm{CH}$ moiety of the acac ligand was observed, excluding the possibility that the dynamic process is related to a multiple species equilibrium. More likely, the temperature-dependence seen in the spectra is related to the hindered rotation of the acac fragment about the $\mathrm{Au}-\mathrm{C}$ bond, which is slowed by the interaction between one carbonyl and a silver cation (see Figure 6). This is further confirmed by the large difference in the ${ }^{13} \mathrm{C}$ NMR shifts between the two carbonyl groups of the acac fragment $\left(\delta_{\mathrm{C}}=203.4\right.$ and $\left.212.9 \mathrm{ppm}\right)$. It is reasonable to assume that this interaction induces an oscillating slippage of the pyrazine pincers within the aggregate, which is fast enough to equalize the chemical shift of the complex at room temperature. When the slippage is slowed on cooling, the two sides of the pincer become magnetically inequivalent and two sets of signals are observed. 

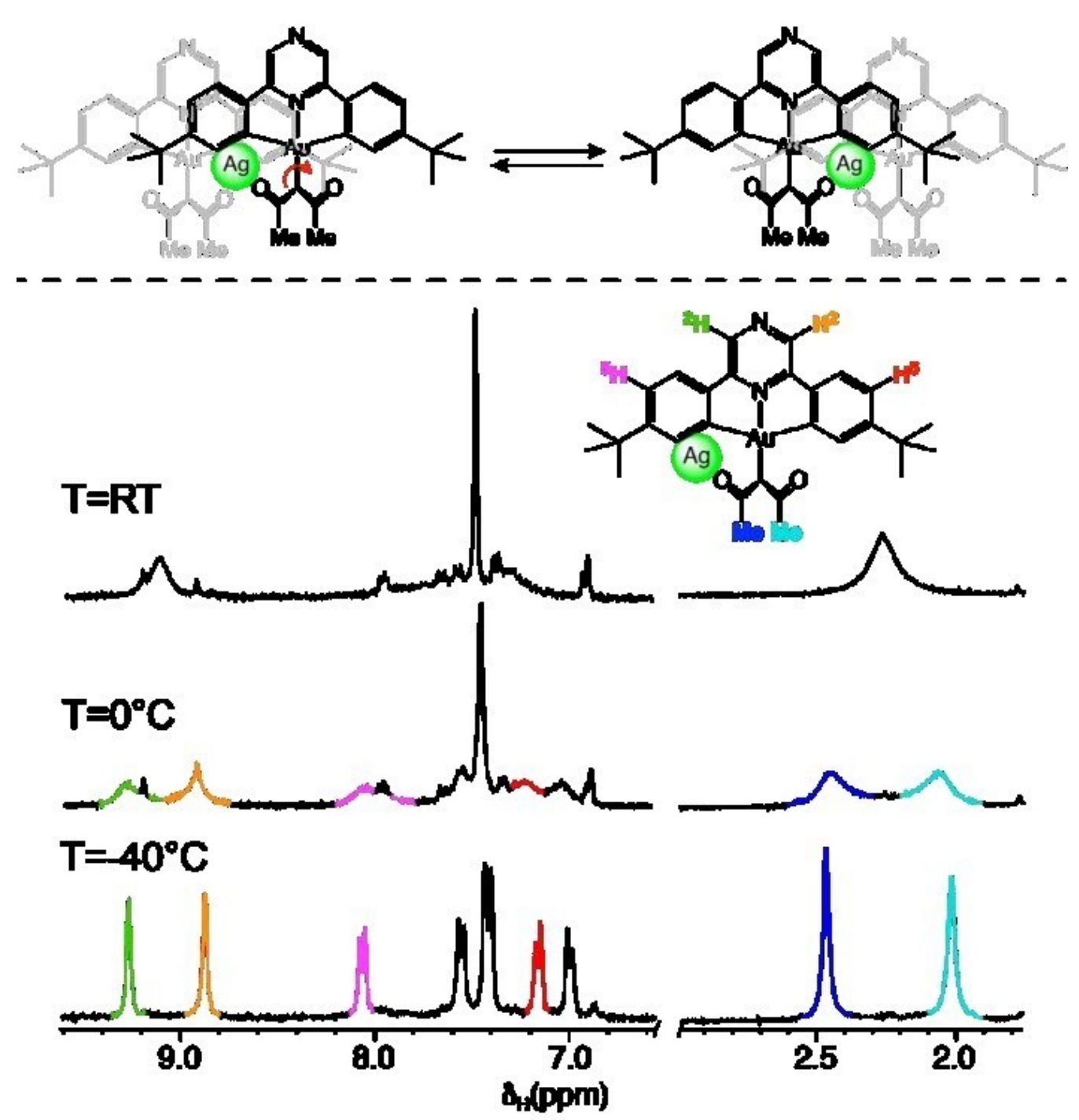

Figure 6. VT ${ }^{1} \mathrm{H}$ NMR spectra of $\mathbf{3 S b F}_{\mathbf{6}}$ and oscillating slippage in $\left[\left\{\left\{\left(\mathrm{C}^{\wedge} \mathrm{Npz}^{\wedge} \mathrm{C}\right) \mathrm{Au}(\mathrm{acac})_{2}\right\}_{2} \mathrm{Ag}\right\}\left\{\mathrm{Ag}_{2} \mathrm{X}_{4}\right\}\right]_{2}$ core.

The degree of association in solution of $\mathbf{3 S b F}_{\mathbf{6}}$, and $\mathbf{3 C l O}_{4}$ was investigated by means of diffusion NMR spectroscopy. ${ }^{19}$ In particular, ${ }^{1} \mathrm{H}$ PGSE NMR experiments on $\mathbf{3 S b F}_{6}$ and $\mathbf{3 C l O}_{4}$ have been performed as a function of the concentration in $\mathrm{CD}_{2} \mathrm{Cl}_{2}$ and the data were interpolated by assuming the shape of the complexes as that of a prolate ellipsoid, using crystallographic data as a tool for volume calculations (see Supporting Information for details). We also included the monomeric precursor $\left(\mathrm{C}^{\wedge} \mathrm{N}^{\mathrm{pz} \wedge} \mathrm{C}\right) \mathrm{Au}(\mathrm{acac})$ in order to have a direct comparison.

The monomeric precursor has no self-aggregation tendency over a 1-25 $\mathrm{mM}$ concentration range, as the measured $P$ parameter (which is directly proportional to the hydrodynamic radius) which does not change with concentration and matches the one calculated for the monomer (Figure 7). This is in contrast with our previous 
observations on pyrazine-based gold thiolate complexes, where a modest selfaggregation due to $\pi-\pi$ stacking interactions was observed at concentrations higher than $10.0 \mathrm{mM} .{ }^{8}$ In this case, it seems likely that the acetylacetonate moiety disrupts this weak interaction network, making stacking in solution more difficult. On the other hand, $P$ 90 values measured for both $\mathbf{3 C l O}_{4}$ and $\mathbf{3 S b F}_{6}$ are comparably larger. For instance, at $c=$ $6.0 \mathrm{mM}$ the $P$ value for $\mathbf{3 S b F} 6$ is twice that of the monomeric $\left(\mathrm{C}^{\wedge} \mathrm{N}^{\mathrm{pz} \wedge} \mathrm{C}\right) \mathrm{Au}(\mathrm{acac})$ complex and matches the one calculated from the crystal structure for the intact tetramer. This indicates that the aggregate structure of

$\left[\left\{\left\{\left(\mathrm{C}^{\wedge} \mathrm{N}^{\mathrm{pz} \wedge} \mathrm{C}\right) \mathrm{Au}(\mathrm{acac})\right\}_{2} \mathrm{Ag}\right\}\left\{\mathrm{Ag}_{2}\left(\mathrm{SbF}_{6}\right)_{4}\right\}\right]_{2}$ is retained in solution. Interestingly, $P$

values are independent of the concentration, even below $1.0 \mathrm{mM}$, meaning that the complexes do not dissociate on dilution. The behavior of $\mathbf{3 C l O}_{4}$ matches that of $3 \mathrm{SbF}_{6}$ within the experimental error, suggesting that there is no anion effect on the aggregation tendency of these species.

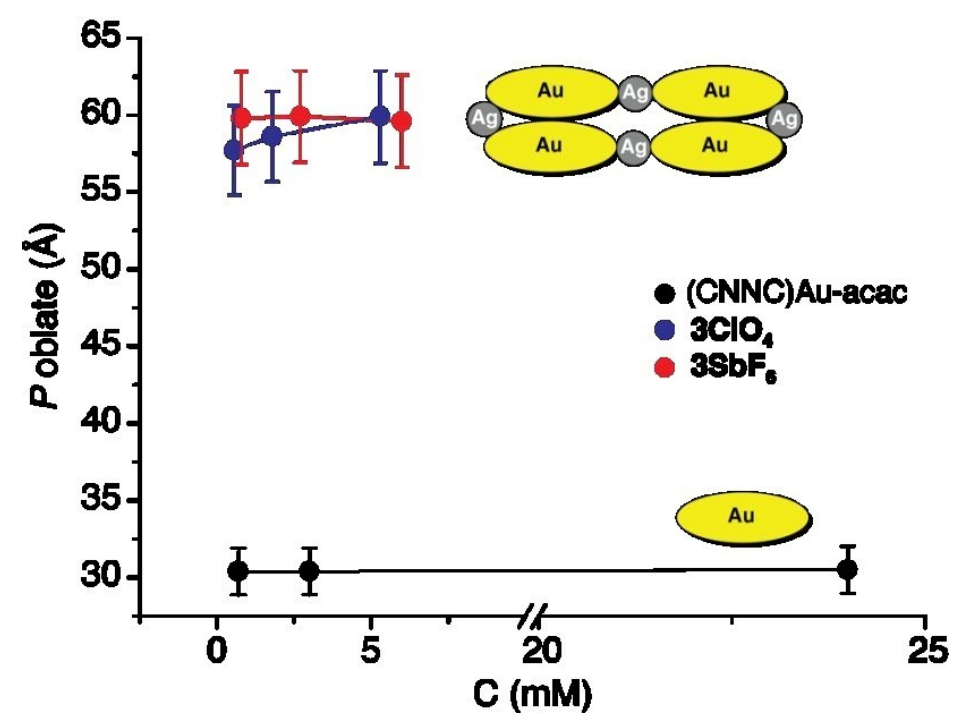

Figure 7. ${ }^{1} \mathrm{H}$ PGSE NMR experiments on $\mathbf{3 S b F}_{6}, \mathbf{3 C l O}_{4}$ and $\left[{ }^{\mathrm{pz}} \mathrm{Au}\right]$ acac.

Photophysical properties. Since we discovered that polymethylmethacrylate (PMMA) and polyvinylcarbazole (PVK) are capable of breaking some of these aggregates, regenerating the starting materials, the photoluminescence was probed in polystyrene (PS), in which the colors of the aggregates and the emissions are closely similar to the solids but show increased intensities. For comparison the photophysical properties of the corresponding gold precursor complexes were also measured in polystyrene. A summary of the emissions $\lambda_{\mathrm{em}}$, the lifetimes $\tau$ and photoluminescent 
quantum yields $\phi$ is given in Table 1. For the complexes with adequate solubility, the UV-vis absorption and photoluminescence spectra have also been recorded in solution (see ESI, Tables S3.1 and S3.2).

Table 1 Photoluminescent properties of the Au-Ag complexes in PS (10\%).

\begin{tabular}{|c|c|c|c|}
\hline Complex & $\lambda_{\mathrm{em}} / \mathrm{mm}\left(\lambda_{\mathrm{ex}} / \mathrm{mm}\right)$ & $\tau \pm \mathrm{sd} / \mathrm{ns}(\mathrm{contr} . / \%)\left[\lambda_{\mathrm{em}} / \mathrm{mm}\right]$ & $\begin{array}{c}\phi / \% \\
/ \mathrm{nm}) \\
\left(\lambda_{\mathrm{ex}}\right.\end{array}$ \\
\hline$\left[{ }^{p z} \mathbf{A u}\right] \mathbf{C N}$ & $\begin{array}{l}542_{\max }, 570 \operatorname{sh}(361, \\
392 \operatorname{sh}, 430,457,484)\end{array}$ & $1702 \pm 38(75), 350 \pm 20(22)^{\mathrm{b}}[542]$ & $4.6(420)$ \\
\hline $\mathbf{1 S b F}_{6}$ & $\begin{array}{l}567,601_{\max }, 642 s h(366 \\
429,453,488,528)\end{array}$ & $1292 \pm 20(70), 216 \pm 9(22)^{b}[601]$ & $7.2(480)$ \\
\hline $\mathrm{1ClO}_{4}$ & $\begin{array}{l}570,610_{\max }, 653 \operatorname{sh}(366, \\
415 s h, 488,529)\end{array}$ & $1638 \pm 33(73), 369 \pm 21(25)^{\mathrm{b}}[610]$ & $\begin{array}{l}10.3 \\
(480)\end{array}$ \\
\hline$\left[{ }^{\text {tBu-py }} \mathbf{A u}\right] \mathbf{C N}$ & $\begin{array}{l}482_{\max }, 517,550 \operatorname{sh}(300- \\
350,365,381 \operatorname{sh}, 408)^{\mathrm{a}}\end{array}$ & $1360 \pm 15(76), 234 \pm 6(22)^{b}[482]$ & $\begin{array}{l}<1 \\
(370)\end{array}$ \\
\hline $2 \mathrm{SbF}_{6}$ & $\begin{array}{l}465 s h, 477_{\max }, 514, \\
547 \operatorname{sh}(320-370,385)\end{array}$ & $1191 \pm 13(75), 201 \pm 6(22)^{b}[477]$ & $2.3(370)$ \\
\hline $2 \mathrm{ClO}_{4}$ & $\begin{array}{l}486_{\max }, 517,547 s h(320- \\
350,372,390,415)\end{array}$ & $1280 \pm 15(72), 240 \pm 3(28)^{b}[486]$ & $2.6(370)$ \\
\hline$\left[{ }^{\mathrm{pz}} \mathrm{Au}\right] \mathbf{a c a c}$ & $\begin{array}{l}470,483 s h, 525_{\max }, 557 \\
(325,355,400,423,443)\end{array}$ & $1589 \pm 39(72), 356 \pm 22(25)^{\mathrm{b}}[525]$ & $\begin{array}{l}<1 \\
(415)\end{array}$ \\
\hline $3 \mathrm{SbF}_{6}$ & $520 s h, 582_{\max }(300-500)$ & $1563 \pm 38(72), 337 \pm 21(25)^{b}[582]$ & $3.9(460)$ \\
\hline $3 \mathrm{ClO}_{4}$ & $\begin{array}{l}515 s h, 560_{\max }, 587 s h \\
(300-500)\end{array}$ & $1637 \pm 27(71), 353 \pm 16(26)^{\mathrm{b}}[560]$ & $6.9(470)$ \\
\hline$\left[{ }^{\mathrm{py}} \mathrm{Au}\right] \mathrm{acac}$ & $450^{\mathrm{a}}$ & & \\
\hline $4 \mathrm{SbF}_{6}$ & $\begin{array}{l}465 s h, 498_{\max }, 530 \mathrm{sh}, \\
564 \operatorname{sh}(300-420)\end{array}$ & $1352 \pm 40(70), 322 \pm 19(30)^{\mathrm{b}}[498]$ & $2.2(370)$ \\
\hline$\left[{ }^{p z} \mathrm{Au}\right] \mathrm{mln}$ & $\begin{array}{l}500 s h, 542_{\max }, 572 s h \\
(367-482)\end{array}$ & $132(10), 800(90)[542]$ & $5.8(370)$ \\
\hline $\mathbf{5 S b F}_{6}$ & $566_{\max }, 593 \operatorname{sh}(340-480)$ & $240(15), 1121(85)[560]$ & $9.4(440)$ \\
\hline $\mathrm{5ClO}_{4}$ & $\begin{array}{l}562_{\max }, 592 \operatorname{sh}(323,370, \\
445-474)\end{array}$ & $231(12), 1356(88)[562]$ & $8.8(440)$ \\
\hline
\end{tabular}

As mentioned before, the cyanide pyrazine complexes $\mathrm{1SbF}_{6}$ and $\mathrm{1ClO}_{4}$ are poorly soluble in dichloromethane. For this reason, the usual experimental methodology of mixing a $\mathrm{CH}_{2} \mathrm{Cl}_{2}$ solution of the complex with a $\mathrm{CH}_{2} \mathrm{Cl}_{2}$ solution of the polymer to prepare the doped film was unsuccessful and produced very poor dispersions. We therefore used the alternative strategy of mixing $\left(\mathrm{C}^{\wedge} \mathrm{N}^{\mathrm{pz} \wedge} \mathrm{C}\right) \mathrm{AuCN}$ with the PS in 
$\mathrm{CH}_{2} \mathrm{Cl}_{2}$ and adding the silver salt to this solution while sonicating. This generates clear films suitable for accurate measurements.

As can be seen in Figure 8, there is a red-shift of the emission maxima of the cyanide silver complexes relative to the precursor $(601 \mathrm{~nm} \mathbf{1 S b F} ; 610 \mathrm{~nm} \mathrm{1ClO}$, 542 $\left.\mathrm{nm}\left[{ }^{\mathrm{pz}} \mathbf{A u}\right] \mathbf{C N}\right)$. Despite the low solubility, the excitation band of the PS films is well resolved. The vibrational progression of the $\mathrm{C}^{\wedge} \mathrm{N}^{\wedge} \mathrm{C}$ pincer ligands is retained in both aggregates. This is indicative of the participation of the $\mathrm{C}^{\wedge} \mathrm{N}^{\wedge} \mathrm{C}$ in the orbitals that control these transitions, as is also confirmed by theoretical calculations (see below).

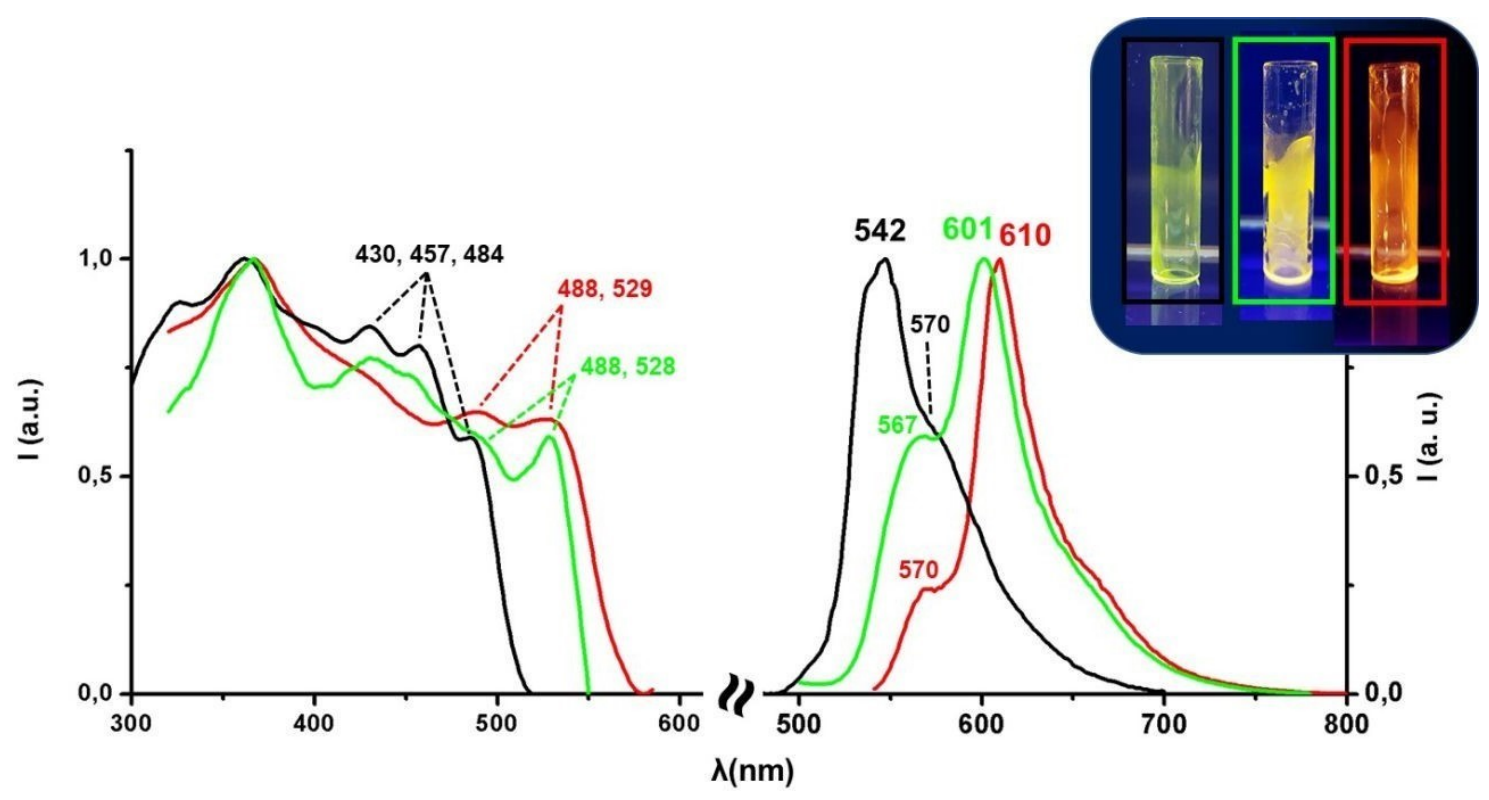

Figure 8: Excitation and emission bands of complexes $\mathbf{1 S b F} 6$ (green lines), $\mathbf{1 C l O}_{4}$ (red lines) and $\left(\mathrm{C}^{\wedge} \mathrm{N}^{\mathrm{pz}} \wedge \mathrm{C}\right) \mathrm{AuCN}$ (black lines) in PS (polystyrene) at a loading of 10 weight$\%$. The inset shows pictures of the PS films used for the measurements under UV light $(365 \mathrm{~nm})$.

In contrast to this, the photoluminescence of the $p$-tBu pyridine cyanide series seems much less sensitive to the formation of the silver aggregates. Thus, as can be seen in Figure S3.1, the complexes $\left[\left\{\left(\mathrm{C}^{\wedge} \mathrm{N}^{\mathrm{tBu} \wedge} \mathrm{C}\right) \mathrm{AuCN}\right\}_{2} \mathrm{Ag}\right] \mathrm{X}\left(478 \mathrm{~nm} \mathrm{X}=\mathrm{SbF}_{6} \mathbf{2 S b F}_{6}\right.$, $\left.486 \mathrm{~nm} \mathrm{ClO}_{4} \mathbf{2 C l O}_{4}\right)$ and $\left(\mathrm{C}^{\wedge} \mathrm{N}^{\mathrm{tBu} \wedge} \mathrm{C}\right) \mathrm{AuCN} 481 \mathrm{~nm}$ exhibit very similar emission profiles in the blue/green region.

As mentioned before, the reaction with silver in $\mathrm{CH}_{2} \mathrm{Cl}_{2}$ solution is accompanied by a colour change from the light-yellow of $\left(\mathrm{C}^{\wedge} \mathrm{N}^{\mathrm{pz} \wedge} \mathrm{C}\right) \mathrm{Au}(\mathrm{acac})$ to the deep orange of both aggregates. This is reflected in the red-shifts of the lowest energy absorption bands 
that, in any case, retain the vibrational spacing indicative of the ${ }^{1} \mathrm{IL}\left(\mathrm{C}^{\wedge} \mathrm{N}^{\mathrm{pz} \wedge} \mathrm{C}\right)$

parentage.

Following the same trend, the acac aggregates 3 show intense orange-yellow emissions clearly red-shifted with respect to the precursor in PS (582 nm 3SbF , 560 $\mathrm{nm} 3 \mathrm{ClO}_{4}$ vs. $525 \mathrm{~nm}\left[{ }^{\mathrm{pz}} \mathrm{Au}\right]$ acac) and in $\mathrm{CH}_{2} \mathrm{Cl}_{2}$ solution at room temperature $(569 \mathrm{~nm}$

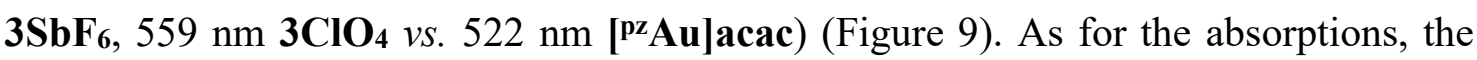
vibrational spacing of the $\mathrm{C}^{\wedge} \mathrm{N}^{\wedge} \mathrm{C}$ ligand indicates the participation of the pincer in the orbitals responsible for the emission. This fact, and the lifetimes in the 1-2 $\mu$ s range, are indicative of a ${ }^{3} \mathrm{IL}\left(\mathrm{C}^{\wedge} \mathrm{N}^{\mathrm{pz} \wedge} \mathrm{C}\right)$ ligand-based triplet origin perturbed by the formation of the polynuclear aggregate for the emissions.

In $\mathrm{CH}_{2} \mathrm{Cl}_{2}$ at $77 \mathrm{~K}$ the energy sequence of the emission is retained $(541 \mathrm{~nm}$ $\left[{ }^{\mathrm{pz}} \mathbf{A u}\right] \mathbf{a c a c}>544 \mathrm{~nm} \mathbf{3 C l O}_{4}>558 \mathrm{~nm} \mathbf{3 S _ { b F }}$ ). Interestingly, while the emission of

[ ${ }^{\mathrm{pz}} \mathbf{A u}$ ] acac at $77 \mathrm{~K}$ is red-shifted with respect to the emission at $298 \mathrm{~K}$, both aggregates show a clear blue-shift of the emission at low temperature. The rigidochromism found for the aggregates is consistent with the participation of the $\mathrm{Ag}$ ions in the frontier orbitals and a mixed ${ }^{3} \mathrm{CT}$ excited state. ${ }^{20}$ This is also confirmed by theoretical calculations (see below).

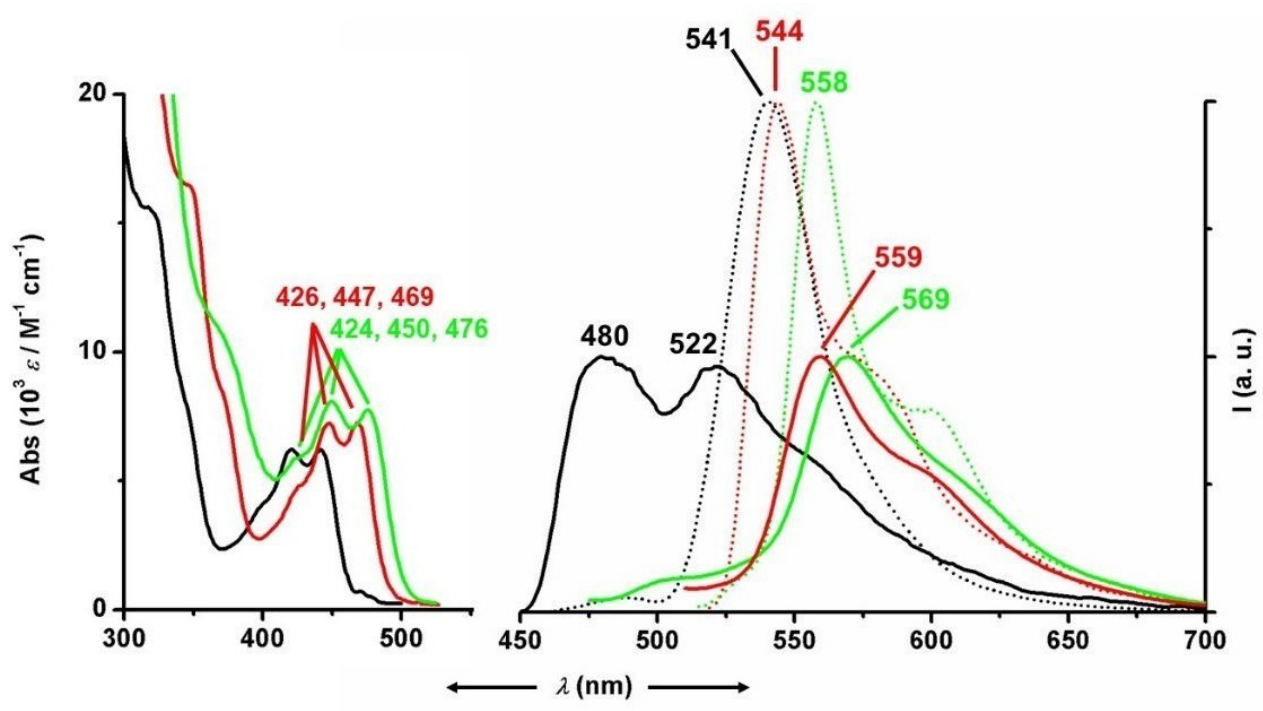

Figure 9. (a) Low energy UV-Vis absorption spectra and (b) emission spectra in $\mathrm{CH}_{2} \mathrm{Cl}_{2}\left(10^{-4} \mathrm{M}\right)$ at $298 \mathrm{~K}$ (solid lines) and at $77 \mathrm{~K}$ (dotted lines) of complexes $\left[{ }^{\mathrm{pz}} \mathrm{Au}\right] \mathbf{a c a c}$ (black), $\mathbf{3 \mathrm { SbF } _ { 6 }}$ (green) and $\mathbf{3 C l O}_{4}(\mathrm{red})$.

While the pyridine acac precursor $\left(\mathrm{C}^{\wedge} \mathrm{N}^{\mathrm{py}} \mathrm{C}\right) \mathrm{Au}(\mathrm{acac})\left[^{\mathbf{p y}} \mathbf{A u}\right] \mathbf{a c a c}$ shows only weak photoluminescence at $298 \mathrm{~K}$ both in $\mathrm{CH}_{2} \mathrm{Cl}_{2}$ and PS, complex 
$\left.\left[\left\{\left(\mathrm{C}^{\wedge} \mathrm{Npy}^{\wedge} \mathrm{C}\right) \mathrm{Au}(\mathrm{acac})_{2}\right\}_{2} \mathrm{Ag}\right\}\right]\left(\mathrm{SbF}_{6}\right) \quad \mathbf{4} \mathbf{S b F}_{\mathbf{6}}$ exhibits intense emissions at room temperature $\left(\lambda_{\max }=498 \mathrm{~nm}, \phi=2.2 \%\right.$ in PS; $\lambda_{\max }=442 \mathrm{~nm}$ in $\left.\mathrm{CH}_{2} \mathrm{Cl}_{2}\right)$. As can beseen in Figure 10, in $\mathrm{CH} \mathrm{Cl}_{2}$ at $77 \mathrm{~K}$ complex $\mathbf{4} \mathbf{S b F}$ and its precursor show similar ${ }^{3} \operatorname{IL}\left(\mathrm{C}^{\wedge} \mathrm{N}^{\wedge} \mathrm{C}\right)$ structured emission profiles. Both the emission maxima and the low energy absorption bands appear slightly red shifted in $\mathbf{4} \mathbf{S b F}_{\mathbf{6}}$ with respect to [ ${ }^{\mathrm{py}} \mathbf{A u}$ ]acac.

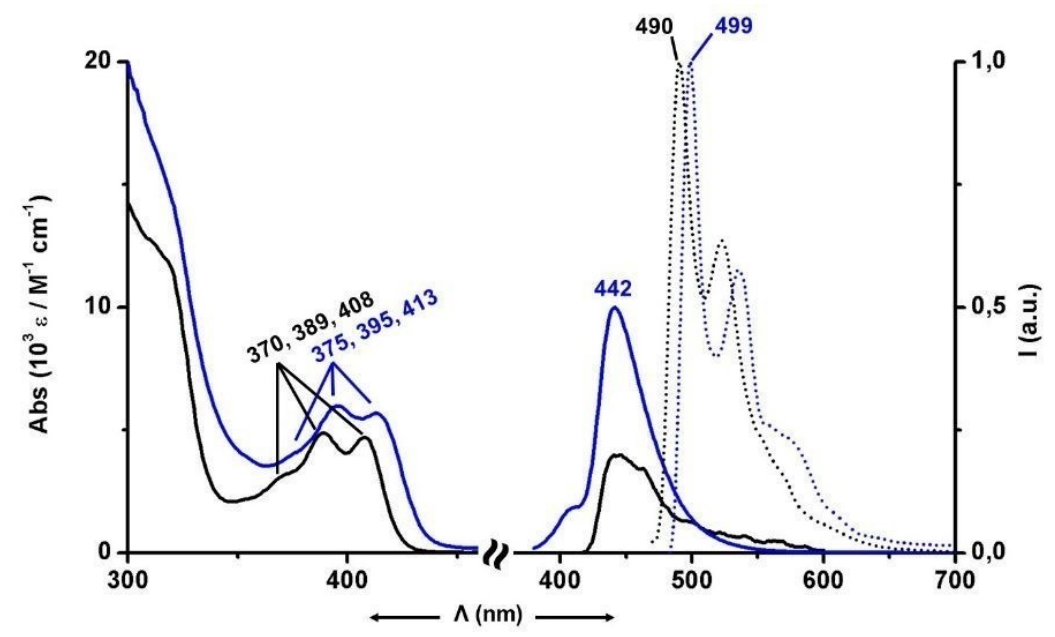

Figure 10: Low energy UV-Vis absorption spectra (a) and emission spectra in $\mathrm{CH} \mathrm{Cl}_{2}$ $\left(10^{-4} \mathrm{M}\right)$ at $298 \mathrm{~K}$ (b, solid lines) and at $77 \mathrm{~K}$ (b, dotted lines) of complexes [ ${ }^{\mathbf{p y}} \mathbf{A u}$ ]acac (black) and $\mathbf{4 S b F} 6$ (blue).

The malononitrile coordination polymer $\left\{\left[\left\{\left(\mathrm{C}^{\wedge} \mathrm{N}^{\mathrm{pz} \wedge} \mathrm{C}\right) \mathrm{Au}(\text { malononitrile })_{2}\right\}_{2-}\right.\right.$ $\left.\mathrm{Ag}(\mathrm{THF})]\left(\mathrm{SbF}_{6}\right)\right\}_{\mathrm{n}} \mathbf{5 S b F}_{\mathbf{6}}$ shows an intense deep-orange emission in PS (566 nm). The red shift with respect to the precursor $\left(\mathrm{C}^{\wedge} \mathrm{N}^{\mathrm{pz} \wedge} \mathrm{C}\right) \mathrm{Au}\left(\right.$ malononitrile) $\left[{ }^{\mathbf{p z}} \mathbf{A u}\right] \mathbf{m l n}(528 \mathrm{~nm})$ (See Figure S3.2) is presumably due to perturbed ${ }^{3} \operatorname{IL}\left(\mathrm{C}^{\wedge} \mathrm{N}^{\mathrm{pz}}{ }^{\wedge} \mathrm{C}\right)$ transitions. As can be seen in Figure S3.2 both complexes $\mathbf{5 S b F}_{6}$ and $\mathbf{5 C l O}_{4}$ show similar emission. The lack of influence of the anion in the photophysical properties is in accordance with the structure of $\mathbf{5 S b F}_{6}$ described before.

\section{Theoretical Calculations.}

To provide a better insight into the nature of the photophysical properties of these aggregates, and in particular to explore the effect that the interaction with the silver centers has on the frontier orbitals of the molecules, we have performed density functional (DFT) and time-dependent density functional theory (TD-DFT) calculations. Details of the calculations can be found in the SI. For comparison and consistency, we also carried out calculations on the mononuclear precursors with the same method. 
It is well stablished that both the lowest energy absorptions and the emissions in $\left(\mathrm{C}^{\wedge} \mathrm{N}^{\wedge} \mathrm{C}\right) \mathrm{AuX}$ complexes are dominated by the cyclometallated ligand as the frontier orbitals are located in this chromophore, with little or no contribution from the $\mathrm{X}$ ligands. ${ }^{1,3,6}$ However, it is also well known that while the frontier orbitals are located on the $\mathrm{C}^{\wedge} \mathrm{N}^{\wedge} \mathrm{C}$ pincer, the energy of the ${ }^{1} \operatorname{IL}\left(\mathrm{C}^{\wedge} \mathrm{N}^{\wedge} \mathrm{C}\right)$ and ${ }^{3} \operatorname{IL}\left(\mathrm{C}^{\wedge} \mathrm{N}^{\wedge} \mathrm{C}\right)$ transitions are indirectly affected by subtle changes in the electronics of the global system. ${ }^{6,8,12}$

As can be seen in Figure 10, for the fragment $\left[\left\{\left(\mathrm{C}^{\wedge} \mathrm{N}^{\mathrm{pz} \wedge} \mathrm{C}\right) \mathrm{AuCN}\right\}_{2} \mathrm{Ag}\right]^{+} \mathbf{1}^{+}$both HOMO and LUMO are mainly located on the $\left(\mathrm{C}^{\wedge} \mathrm{N}^{\mathrm{pz} \wedge} \mathrm{C}\right)$ ligand, with $\mathrm{Au}$ participation in the LUMO. These orbitals mimic the frontier orbitals of the precursor $\left[{ }^{[\mathbf{z}} \mathbf{A u}\right] \mathbf{C N}$. While very similar in shape to $\left[{ }^{\mathbf{z}} \mathbf{A u}\right] \mathbf{C N}$, the orbitals of $\mathbf{1}^{+}$show a smaller HOMOLUMO gap and smaller vertical $\mathrm{S} 0 \rightarrow \mathrm{S} 1$ excitation energy (see $\mathrm{SI}$ ). This is a general trend for all the aggregates: In all cases the frontier orbitals are mainly $\mathrm{C}^{\wedge} \mathrm{N}^{\wedge} \mathrm{C} / \mathrm{Au}$ based orbitals (see S.I.) and the calculations predict a red shift of the lowest energy absorptions and the emissions. These results are consistent with the assignment of the absorption and the emission, respectively, as ${ }^{1} \mathrm{IL}\left(\mathrm{C}^{\wedge} \mathrm{N}^{\wedge} \mathrm{C}\right)$ and ${ }^{3} \operatorname{IL}\left(\mathrm{C}^{\wedge} \mathrm{N}^{\wedge} \mathrm{C}\right)$ transitions perturbed by the formation of the aggregate .

The calculations also show an increase of the oscillator strength of the vertical $\mathrm{S} 0 \rightarrow$ $\mathrm{S} 1$ transition as a consequence of the formation of the aggregate. This is consistent with the rigidity of the aggregates compared with the precursors and explains the increased emission quantum yields of the $\mathrm{Au} / \mathrm{Ag}$ systems compared with the mononuclear precursors.
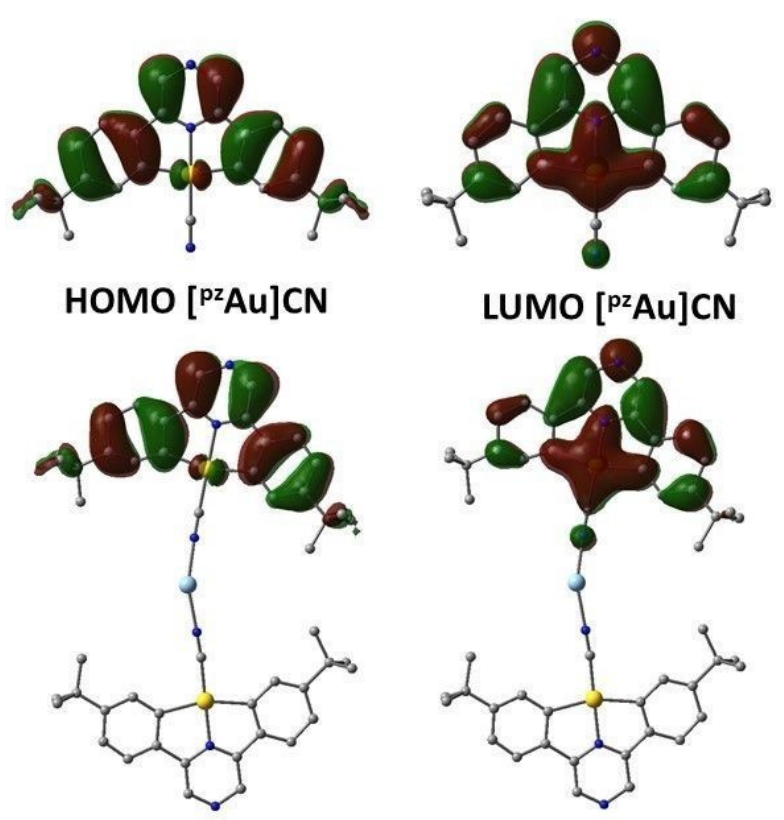

HOMO $\left[\left\{{ }^{\mathrm{pz} A u C N}\right\}_{2} \mathrm{Ag}\right]^{+}$

LUMO [\{ $\left.\left.{ }^{\mathrm{pz}} \mathrm{AuCN}\right\}_{2} \mathrm{Ag}\right]^{+}$ 
Figure 11. HOMO and LUMO frontier orbitals for $\left[{ }^{\mathrm{pz}} \mathbf{A u}\right] \mathbf{C N}$ and $\mathbf{1}^{+}$. Isovalue $=0.02$ $\left(\text { electrons } / \text { bohr }^{3}\right)^{1 / 2}$.

In the acac series, the cyclometallated ligand also plays a predominant role in the composition of the frontier orbitals. However, there is a clear influence of the $\mathrm{Ag}$ centers in some of the orbitals responsible of the photophysical properties. In Figure 12 we include the frontier orbitals of $\mathbf{3 C l O}_{4}$ as an illustrative example. The HOMO orbital is centered in the $\left.\left\{\mathrm{Ag}_{2}(\mathrm{ClO})\right\}_{4}\right\}$ core, while LUMO is centered in the pincer with strong

pyrazine character. The predominance of the pincer in the lowest empty orbitals is a general feature of the series. However, in some cases, we observe orbitals that are delocalized between two $\left(\mathrm{C}^{\wedge} \mathrm{N}^{\mathrm{pz} \wedge} \mathrm{C}\right) \mathrm{Au}$ moieties through the $\mathrm{Ag}^{\mathrm{Td}}$ centers.

The results are consistent with the photophysical properties discussed before, but the complexity of the systems preclude to determinate the role of the silver ions with more detail.
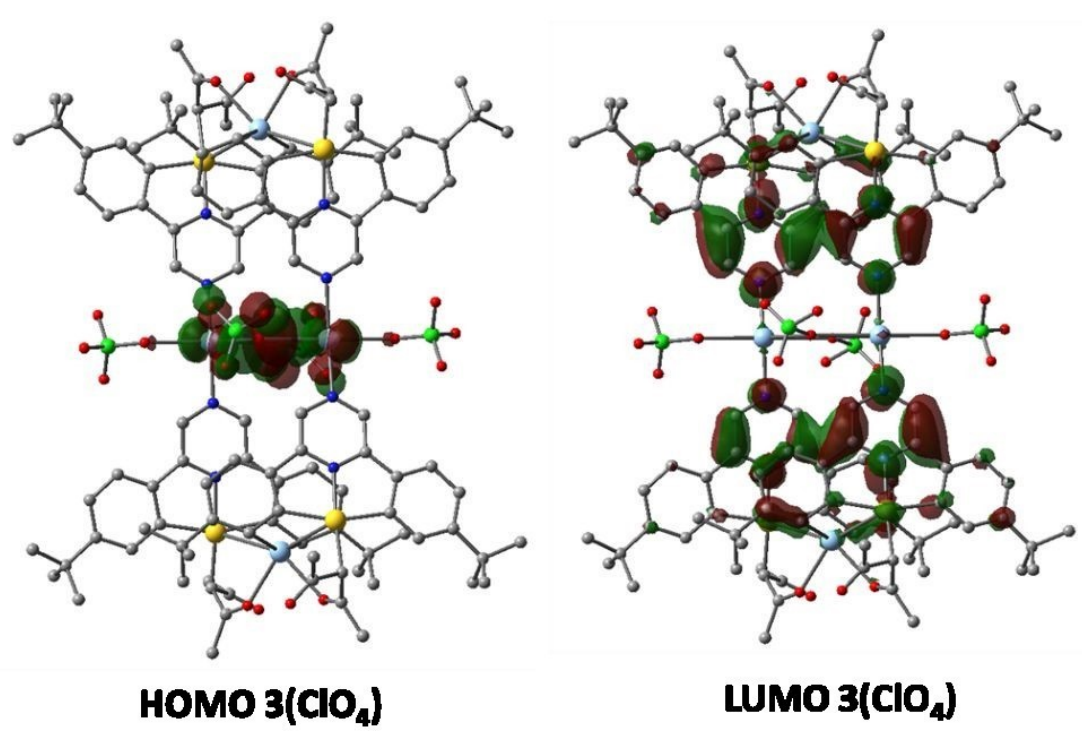

LUMO $3\left(\mathrm{ClO}_{4}\right)$

Figure 12. HOMO and LUMO frontier orbitals for $\mathbf{3 C l O}_{4}$. Isovalue $=0.02$

$\left(\text { electrons } / \text { bohr }^{3}\right)^{1 / 2}$.

\section{Conclusions.}

In summary we have prepared a series of $\mathrm{Au}{ }^{\mathrm{III}} / \mathrm{Ag}^{\mathrm{I}}$ aggregates by employing cyclometallated $\left(\mathrm{C}^{\wedge} \mathrm{N}^{\wedge} \mathrm{C}\right) \mathrm{AuX}$ complexes as building blocks linked by silver ions. The ancillary ligands used (cyanide, acac, malononitrile) act as donors that stabilize the aggregates. In some cases the free nitrogen of the pyrazine-based $\mathrm{Au}^{\mathrm{III}}$ precursors, 
induces the formation of high nuclearity structures. Even anions like $\mathrm{SbF}_{6}^{-}$or $\mathrm{ClO}$, that are typically considered to be weakly coordinating, participate in the stabilization of the multimetallic centers by bridging interactions. The aggregate structures persistin $\mathrm{CH} \mathrm{Cl}_{2}$ solutions. These $\mathrm{Au}$ III/Ag clusters show intense photoluminescence in polystyrene and in solution, with emissions dominated by ${ }^{1} \operatorname{IL}\left(\mathrm{C}^{\wedge} \mathrm{N}^{\wedge} \mathrm{C}\right)$ and ${ }^{3} \operatorname{IL}\left(\mathrm{C}^{\wedge} \mathrm{N}^{\wedge} \mathrm{C}\right)$ transitions perturbed by the aggregation which show strongly enhanced intensities and are red-shifted with respect to the non-aggregated starting materials. Increased oscillator strength of the vertical S0 $\rightarrow$ S1 transition and reduced non-radiative processes are traced to the rigidity of these structures. These results demonstrate a synthetically facile strategy for the generation of compounds with enhanced and easily modulated emissions.

Acknowledgment. This work was supported by the European Research Council and by the Ministerio de Economía y Competitividad (MINECO, project CTQ2016-78463-P). M. B. is an ERC Advanced Investigator Award holder (grant no. 338944-GOCAT). R. J. R. acknowledges the VI PPIT-US for a research fellowship. The computations were made possible by use of the Finnish Grid Infrastructure resources (urn:nbn:fi:researchinfras-2016072533).

Supporting Information (SI) available: Details of synthesis and characterization, Xray crystallography, photophysical properties, theoretical calculations. See DOI: CCDC 1874432-1874437 contain the supplementary crystallographic data for this paper. These data can be obtained free of charge from The Cambridge Crystallographic Data Centre via www.ccdc.cam.ac.uk/data_request/cif.

\section{References}

(1) (a) Tang, M. C.; Chan, A. K. W.; Chan, M. Y.; Yam, V. W.-W. Platinum and Gold Complexes for OLEDs. Top. Curr. Chem. 2016, 374: 46. (b) López-deLuzuriaga, J. M.; Monge, M.; Olmos, M. E. Luminescent aryl-group eleven metal complexes. Dalton Trans. 2017, 46, 2046-2067. (c) Bronner, C; Wenger, O. S. Luminescent cyclometalated gold(III) complexes. Dalton Trans. 2011, 40, 1240912420. (d) Yam, V. W.-W.; Au, V. K.-M.; Leung, S. Y.-L. Light-Emitting SelfAssembled Materials Based on $\mathrm{d}^{8}$ and $\mathrm{d}^{10}$ Transition Metal Complexes. Chem. Rev. 2015, 115, 7589-7728. (c) Wong, K. M.-C.; Chan, M. M.-Y.; Yam, V. W.-W. 
Supramolecular Assembly of Metal-Ligand Chromophores for Sensing and

Phosphorescent OLED Applications. Adv. Mater. 2014, 26, 5558-5568.

(2) (a) Roşca, D.-A.; Wright, J. A.; Bochmann, M. An Element Through the

Looking Glass: Exploring the $\mathrm{Au}-\mathrm{C}, \mathrm{Au}-\mathrm{H}$ and $\mathrm{Au}-\mathrm{O}$ Energy Landscape. Dalton Trans.

2015, 44, 20785-20807. (b) Kumar, K.; Nevado, C. Cyclometalated Gold(III)

Complexes: Synthesis, Reactivity, and Physicochemical Properties. Angew. Chem., Int. Ed. 2017, 56, 1994- 2015. (c) Rocchigiani, L.; Fernandez-Cestau, J.; Agonigi, G.;

Chambrier, I.; Budzelaar, P. H. M.; Bochmann, M. Gold(III) Alkyne Complexes:

Bonding and Reaction Pathways. Angew. Chem., Int. Ed. 2017, 56, 13861-13865. (d)

Rocchigiani, L.; Fernandez-Cestau, J.; Budzelaar, P. H. M.; Bochmann, M. Reductive Elimination Leading to C-C Bond Formation in Gold(III) Complexes: A Mechanistic and Computational Study. Chem. - Eur. J. 2018, 24, 8893-8903. (e) Currie, L.;

Rocchigiani, L.; Hughes, D. L.; Bochmann, M. Carbon-Sulfur Bond Formation by Reductive Elimination of Gold(III) Thiolates. Dalton Trans. 2018, 47,6333-6343.

(3) (a) Yam, V. W.-W.; Wong, K. M. C. Luminescent Metal Complexes of $\mathrm{d}^{6}, \mathrm{~d}^{8}$ and $\mathrm{d}^{10}$ Transition Metal Centres. Chem. Commun. 2011, 47, 11579-11592. (b) Tang, M.-C.; Chan, C. K.-M.; Tsang, D. P.-K.; Wong, Y.-C.; Chan, M. M.-Y.; Wong, K. M.C.; Yam, V. W.-W. Saturated Red-Light-Emitting Gold(III) Triphenylamine Dendrimers for Solution-Processable Organic Light-Emitting Devices. Chem. - Eur. J. 2014, 20, 15233-15241. (c) Tang, M.-C.; Lee, C.-H.; Ng, M.; Wong, Y.-C.; Chan, M.Y.; Yam, V. W.-W. Highly Emissive Fused Heterocyclic Alkynylgold(III) Complexes for Multiple Color Emission Spanning from Green to Red for Solution-Processable Organic Light-Emitting Devices. Angew. Chem., Int. Ed. 2018, 57, 5463-5466. (d) Tang, M.-C.; Lee, C.-H.; Lai, S.-L.; Ng, M.; Chan, M.-Y.; Yam, V. W.-W. Versatile Design Strategy for Highly Luminescent Vacuum-Evaporable and Solution-Processable Tridentate Gold(III) Complexes with Monoaryl Auxiliary Ligands and Their Applications for Phosphorescent Organic Light Emitting Devices. J. Am. Chem. Soc. 2017, 139, 9341-9349. (e) To, W.-T.; Tong, G. S. M.; Cheung, C.-W.; Yang, C.; Zhou, D.; Che, C.-M. Luminescent Cyclometalated Gold(III) Alkyl Complexes: Photophysical and Photochemical Properties. Inorg. Chem. 2017, 56, 5046-5059. (f) Sun, C.-Y.; To, W.-P.; Wang, X.-L.; Chan, K.-T.; Su, Z.-M.; Che, C.-M. Metal-Organic framework Composites with Luminescent Gold(III) Complexes. Strongly Emissive and Long-Lived Excited States in Open Air and Photo-Catalysis. Chem. Sci. 2015, 6, 7105-7111.(g)

Cheng, G.; Chan, K. T.; To, W.; Che, C.-M. Color Tunable Organic Light Emitting 
Devices with External Quantum Efficiency over 20\% Based on Strongly Luminescent Gold(III) Complexes having Long-Lived Emissive Excited States. Adv. Mater. 2014, 26, 2540-2546.

(4) (a) Szentkuti, A.; Bachmann, M.; Garg, J. A.; Blacque,O.; Venkatesan, K. Monocyclometalated Gold(III) Monoaryl Complexes-A New Class of Triplet Phosphors with Highly Tunable and Efficient Emission Properties. Chem. - Eur. J. 2014, 20, 2585 - 2596; (b) Szentkuti, A.; Garg, J. A.; Blacque, O.; Venkatesan, K.

Monocyclometalated Gold(III) Complexes Bearing $\pi$-Accepting Cyanide Ligands:

Syntheses, Structural, Photophysical, and Electrochemical Investigations. Inorg. Chem.

2015, 54, 10748-10760. (c) Zehnder, T. N.; Blacque, O.; Venkatesan, K. Luminescent Monocyclometalated Cationic Gold(III) Complexes: Synthesis, Photophysical

Characterization and Catalytic Investigations. Dalton Trans. 2014, 43, 11959-11972.

(d) Bachmann, M.; Blacque, O.; Venkatesan, K. Harnessing White-Light Luminescence Via Tunable Singlet-and Triplet-Derived Emissions Based on Gold(III) Complexes.

Chem. - Eur. J. 2017, 23, 9451 - 9456.

(5) Supramolecular aggregation: (a) Fu, H. L.-K.; Yam, V. W.-W.

Supramolecular Metallogels of Platinum(II) and Gold(III) Complexes. Chem. Lett. 2018, 47, 605-610. (b) Yim, K.-C.; Au, V. K.-M.; Wong, K. M.-C.; Yam, V. W.-W. Luminescent Bis-Cyclometalated Gold(III) Complexes with Alkynyl Ligands of Hexaphenylbenzene and Hexabenzocoronene Derivatives and Their Supramolecular Assembly. Chem. - Eur. J. 2017, 23, 5772-5786. (c) Yim, K.-C.; Au, V. K.-M.; Hung, L.-L.; Wong, K. M.-C.; Yam, V. W.-W. Luminescent Dinuclear Bis-Cyclometalated Gold(III) Alkynyls and Their Solvent-Dependent Morphologies through Supramolecular Self-Assembly. Chem. - Eur. J. 2016, 22, 16258 - 16270.

(6) Fernandez-Cestau, J.; Bertrand, B.; Blaya, M.; Jones, G. A.; Penfold, T. J.; Bochmann, M. Synthesis and Luminescence Modulation of Pyrazine-Based Gold(III) Pincer Complexes. Chem. Commun. 2015, 51, 16629-16632.

(7) To, W.-P.; Zhou, D.; Tong, G. S. M.; Cheng, G.;Yang, C.; Che, C.-M. Highly Luminescent Pincer Gold(III) Aryl Emitters: Thermally Activated Delayed Fluorescence and Solution-Processed OLEDs. Angew. Chem., Int. Ed. 2017, 56, 1403614041.

(8) Currie, L.; Fernandez-Cestau, J.; Rocchigiani, L.; Bertrand, B.; Lancaster, S. J.; Hughes, D. L.; Duckworth, H.; Jones, S. T. E.; Credgington, D.; Penfold, T. J.; Bochmann, M. Luminesceny Gold(III) Thiolates: Supramolecular Interactions Trigger 
and Control Switchable Photoemissions from Bimolecular Excited States. Chem. - Eur. J. 2017, 23, 105-113.

(9) (a) Schmidbaur, H.; Schier, A. A Briefing on Aurophilicity. Chem. Soc. Rev. 2008, 37, 1931-1951 and references therein. (b) Gil-Rubio, J.; Vicente, J. The Coordination and Supramolecular Chemistry of GoldMetalloligands. . Chem. - Eur. J. 2018, 24, 32-46.

(10) Aliprandi, A.; Genovese, D.; Mauro, M.; De Cola, L. Recent Advances in Phosphorescent Pt(II) Complexes Featuring Metallophilic Interactions: Properties and Applications. Chem. Lett. 2015, 44, 1152-1169 and references therein.

(11) (a) Lu, W.; Chan, K. T.; Wu, S.-X.; Chen, Y.; Che, C.-M. Quest for an Intermolecular $\mathrm{Au}(\mathrm{III}) \cdots \mathrm{Au}(\mathrm{III})$ Interaction between Cyclometalated Gold(III) Cations. Chem. Sci. 2012, 3, 752-755. (b) Chan, K. T.; Tong, G. S. M.; Wan, Q.; Cheng, G.; Yang, C.; Che, C.-M. Strongly Luminescent Cyclometalated Gold(III) Complexes Supported by Bidentate Ligands Displaying Intermolecular Interactions and Tunable Emission Energy. Chem. Asian J. 2017, 12, 2104-2120.

(12) Fernandez-Cestau, J.; Bertrand, B.; Pintus, A.; Bochmann, M. Synthesis, Structures, and Properties of Luminescent $\left(\mathrm{C}^{\wedge} \mathrm{N}^{\wedge} \mathrm{C}\right)$ gold(III) Alkyl Complexes: Correlation between Photoemission Energies and C-H Acidity. Organometallics 2017, 36, 3304-3312.

(13) Kettle, S. F. A.; Diana, E.; Boccaleri, E.; Stanghellini, P. L. The Vibrational Spectra of the Cyanide Ligand Revisited. Bridging Cyanides. Inorg. Chem. 2007, 46, 2409-2416.

(14) Bondi, A. Van der Waals Volumes and Radii. J. Phys. Chem. 1964, 68, 441451.

(15) Schmidbaur, H.; Schier, A. Argentophilic Interactions. Angew. Chem. Int. Ed. 2015, 54, 746-784.

(16) Chih, Y.-C., Jing Y.-Z., Hon, M.-L. Argentophilic Interactions and Anionic Control of Supramolecular Structures in Simple Silver Pyridine Complexes. Inorg. Chim. Acta 2007, 360, 21-30.

(17) (a) Smith, H. G.; Rundle, R. E. The Silver Perchlorate-Benzene Complex, $\mathrm{C}_{6} \mathrm{H}_{6} \cdot \mathrm{AgClO}_{4}$, Crystal Structure and Charge Transfer Energy. J. Am. Chem. Soc. 1958, 80, 5075-5080. (b) Ogawa, K.; Kitagawa, T.; Ishida, S.; Komatsu, K. Synthesis and Structure of a New Tetrakis(pentafluorophenyl)borate Salt of the Silver(I) Cation with Novel Trigonal Planar Tris(benzene) Coordination. Organometallics 2005, 24, 4842- 
4844. (c) Fernandez, E. J.; Laguna, A.; Lopez-de-Luzuriaga, J. M.; Olmos, M. E.;

Puelles, R. C. Vapochromism in Complexes of Stoichiometry $\left[\mathrm{Au}_{2} \mathrm{Ag}_{2} \mathrm{R}_{4} \mathrm{~L}_{2}\right]_{\mathrm{n}} . Z$.

Naturforsch. B 2009, 64, 1500-1512. (d) Savjani, N.; Roşca, D.-A.; Schormann, M.;

Bochmann, M.; Gold(III) Olefin Complexes. Angew. Chem. Int. Ed. 2013, 52, 874-877.

(18) Schultheiss, N.; Powell, D. R.; Bosch, E. Silver(I) Coordination Chemistry of 2,6-Diarylpyrazines. $\pi$-Stacking, Anion Coordination, and Steric Control. Inorg. Chem. 2003, 42, 5304-5310.

(19) Rocchigiani, L.; Macchioni, A. Disclosing the Multi-Faceted World of Weakly Interacting Inorganic Systems by Means of NMR Spectroscopy. Dalton Trans. 2016, 45, 2785-2790.

(20) (a) Zanoni, K. P. S.; Kariyazaki, B. K.; Ito, A.; Brennaman, M. K.; Meyer, T. J.; Iha, N. Y. M. Blue-Green Iridium(III) Emitter and Comprehensive Photophysical Elucidation of Heteroleptic Cyclometalated Iridium(III) Complexes. Inorg. Chem. 2014, 53, 4089-4099. (b) Mydlak, M.; Yang, C.-H.; Polo, F.; Galstyan, A.; Daniliuc, C. G.; Felicetti, M.; Leonhardt, J.; Strassert, C. A.; De Cola, L. Sterically Hindered Luminescent $\mathrm{Pt}^{\mathrm{II}}$-Phosphite Complexes for Electroluminescent Devices. Chem. - Eur. J. 2015, 21, 5161-5172. 


\section{"for Table of Contents use only"}

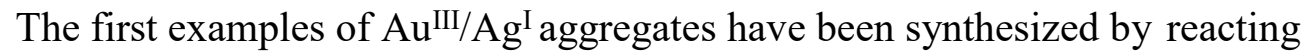
cyclometallated $\left(\mathrm{C}^{\wedge} \mathrm{N}^{\wedge} \mathrm{C}\right) \mathrm{AuX}\left(\mathrm{HC}^{\wedge} \mathrm{N}^{\wedge} \mathrm{CH}=2,6\right.$-bis(4-Bu ${ }^{\dagger} \mathrm{C}$ H $)$ pyrazine; 2,6-bis(4$\left.\mathrm{Bu}^{\mathrm{t}} \mathrm{C}_{6} \mathrm{H}_{4}\right)$ pyridine; 2,6-bis $\left(4-\mathrm{Bu}^{\mathrm{t}} \mathrm{C}_{6} \mathrm{H}_{4}\right) 4-\mathrm{Bu}{ }^{t}$ pyridine) (X = cyanide; - $\mathrm{CH}(\mathrm{COMe})_{2}$, $\mathrm{CH}(\mathrm{CN})_{2}$ with silver salts $\mathrm{AgSbF}_{6}$ and $\mathrm{AgClO}_{4}$. The polynuclear structural arrangements are determined by the nature of the $\mathrm{Au}^{\mathrm{III}}$ fragments, with the counter anions of the silver salts playing an important supportive role. The $\mathrm{Au}^{\mathrm{III}} / \mathrm{Ag}^{\mathrm{I}}$ aggregates are brightly luminescent, with red-shifted emissions and the enhanced intensities compared to the monomeric $\left(\mathrm{C}^{\wedge} \mathrm{N}^{\wedge} \mathrm{C}\right) \mathrm{AuX}$ precursors.

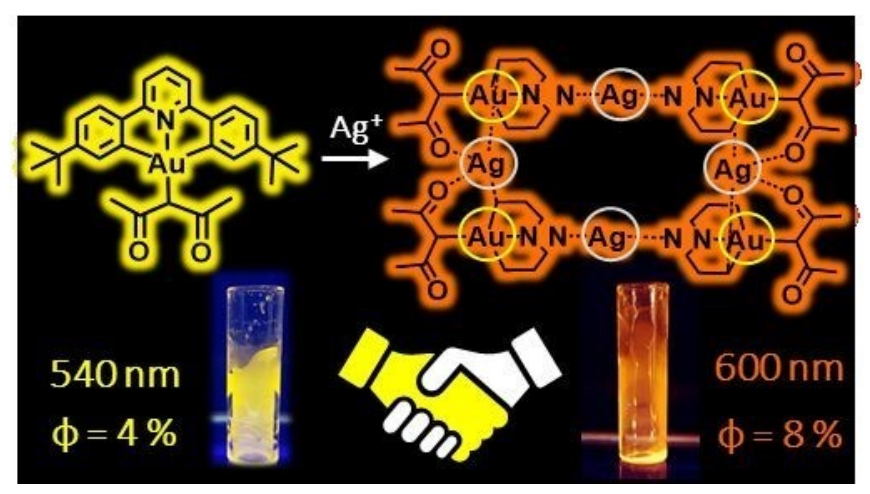

